\title{
Existing evidence on the outcomes of wildlife translocations in protected areas: a systematic map
}

\author{
Joseph Langridge, Romain Sordello * (i) and Yorick Reyjol
}

\begin{abstract}
Background: Ecosystem degradation, mainly through overexploitation and destruction of natural habitats, is a wellknown threat to the viability and persistence of many species' populations worldwide. The use of translocations as a viable conservation tool in conjunction with protected areas has been rapidly increasing over the last few decades. Protected areas such as strict nature reserves, national parks, and species management areas continue to be central tools for biodiversity conservation as they provide vital habitats set aside from various human pressures. Because action consistently runs ahead of policy, the need for a clearer evidence base on the outcomes of wildlife translocations undertaken at a global scale is becoming increasingly urgent for scientific and decision-making communities, in order to build clear strategy frameworks around conservation translocations. We therefore conducted a systematic mapping exercise to provide an overview of the existing evidence on the outcomes of wildlife translocations in protected areas.
\end{abstract}

Methods: We searched two bibliographic databases, four web-based search engines with search-by-key-words capacity, 5 specialist websites, and conducted a grey literature call through two project stakeholders. We screened articles by title, abstract, and full text using pre-defined inclusion criteria all the while assessing the consistency of the reviewers. All relevant translocations were coded from retained publications. Key variables of interest were extracted and coded for each translocation event. The quantity and characteristics of the available evidence and knowledge gaps/clusters are summarised. The distribution and frequency of translocations are presented in heat- and geographical maps.

Review findings: A total of 613 articles were considered eligible for coding bibliometric data. Metapopulation management and review articles were not coded for quantitative and qualitative variables. Linked data (duplicated translocations) were also excluded. Finally, 841 studies of different translocation events were fully coded from 498 articles. Most of these translocations were carried out in North America and Oceania. The most commonly undertaken intervention types were one-off supplementations and "supplemented reintroductions". Mammals were by far the most transferred group among animals. Magnoliopsida was the most translocated plant group. Survival, space use, and demography metrics were the most studied outcomes on translocated species.

Conclusions: This systematic map provides an up-to-date global catalogue of the available evidence on wildlife translocations to, from, or within protected areas. It should enable protected area managers to better understand their role in the global network of protected areas, regarding translocation practice, both as suppliers or recipients of

*Correspondence: romain.sordello@mnhn.fr

UMS PatriNat OFB-MNHN-CNRS, 36 rue Geoffroy-Saint-Hilaire CP41,

75005 Paris, France

(c) The Author(s) 2021. Open Access This article is licensed under a Creative Commons Attribution 4.0 International License, which permits use, sharing, adaptation, distribution and reproduction in any medium or format, as long as you give appropriate credit to the original author(s) and the source, provide a link to the Creative Commons licence, and indicate if changes were made. The images or other third party material in this article are included in the article's Creative Commons licence, unless indicated otherwise in a credit line to the material. If material is not included in the article's Creative Commons licence and your intended use is not permitted by statutory regulation or exceeds the permitted use, you will need to obtain permission directly from the copyright holder. To view a copy of this licence, visit http://creativecommons.org/licenses/by/4.0/. The Creative Commons Public Domain Dedication waiver (http://creativeco mmons.org/publicdomain/zero/1.0/) applies to the data made available in this article, unless otherwise stated in a credit line to the data. 
translocated species. It may help managers and practitioners make their own choices by comparing previous experiences, regarding both the species concerned and the precise translocation modalities (number of individuals, etc.). Finally, it constitutes a decision-making tool for managers as well as for policy makers for future translocations.

Keywords: Managed relocations, Reintroduction, Reinforcement, Supplementation, Ecological replacements, Assisted migration, Rewilding, Conservation areas

\section{Background}

Ecosystem degradation, mainly through overexploitation and destruction of natural habitats, is a wellknown threat to the viability and persistence of many species' populations worldwide [1-5]. According to the IUCN's Global Species Programme, more than 35,000 species across the globe are currently threatened with extinction [6]. Today, species extinction rates are 100 to 1000 times greater than the natural background level, with populations of wild species declining at a rate of 0.5 to $1 \%$ per annum on average [7-11]. Indeed, the major causes of this global biodiversity crisis are anthropogenic in nature, and exacerbated by ongoing climate changes [10]. However, protected areas (i.e. "a clearly defined geographical space, recognised, dedicated and managed, through legal or other effective means, to achieve the long-term conservation of nature [...]" [12]) such as wilderness areas, national parks, and habitat or species management areas continue to be central tools for biodiversity conservation as they provide vital habitats, set aside from various human pressures for the safeguard of species [13-15]. Furthermore, especially in fragmented environments, the role of protected areas is paramount as they provide higher quality habitat often maintaining higher species population levels than other management strategies $[13,16$, 17].

Historically, the intentional movement and release of species has occurred for millennia $[18,19]$, but the use of translocations to address species-focused conservation objectives is a more recent intervention. With several authors advocating the importance of release site habitat quality [e.g. 20-23], the implementation of "intentional movements of organisms from one site for release in another" [18] in conjunction with protected areas may be an increasingly essential conservation strategy. With the overriding pressure of climate change expected to alter habitat suitability for species confined within current protected areas-effectively stranding them as habitat becomes increasingly unfavourable [24]-several authors suggest intentionally moving species between protected areas to where appropriate habitats are currently, or predicted to persist [24-26].
Indeed, different forms of conservation translocations exist, all of which are increasingly recognised as viable means to enhance the resilience of threatened species, improve ecosystem integrity, and assist migration to favourable habitats [25, 27-30]. Firstly, "reintroductions": aim to re-establish viable populations of a focal species within their historical range but from which they have become extirpated or extinct [15]. Secondly, "supplementations": aim to enhance and reinforce population viability by increasing population size and genetic diversity of existing resident populations [18]. Thirdly, "assisted migration": occurs if the persistence of a species in its indigenous range is threatened from current or future impacts than at alternative sites outside of its historical range [15]. In addition, the concept of rewilding has been discussed in the context of climate change [19, 31,32]. The concept was originally based on the keystone role of apex predators and their ability to maintain ecosystem equilibrium through top-down trophic interactions [19]. However, it now includes the role of species reintroductions in order to specifically restore ecological processes or to reestablish an ecological function lost through extinction by means of introducing a suitable related taxa capable of performing a similar ecological role [19]. Further, by reintroducing ecosystem engineers, it has been suggested that this in turn can enhance the albedo effect and contribute to a greater carbon capture and overall negative feedback to global warming [32].

As the above mentioned conservation translocations are being increasingly employed in both terrestrial and marine environments [22, 33, 34], especially reintroductions of threatened species [35-38], the need to summarise this profuse information is ever more apparent for management purposes. In addition, because national and regional protected areas are frequent sites of population restoration action, given that long-term protection from diverse anthropogenic pressures have maintained relatively high-quality habitat [39-42], reserve and wildlife managers alike may be increasingly confronted with the challenges associated with such interventions, i.e. as donor or recipient site managers.

Despite the growing number of these interventions, implementation remains complex and different 
programs have had varying outcomes, which is notably due to the different factors that influence success. From a biological perspective, this may include the level of habitat quality (or protection) at recipient sites [7, 22, $33,43,44]$, the number of translocated individuals [45-48], the distances involved [49], whether acclimatisation measures are used etc. [50,51]. From a social perspective, cost, feasibility, and political acceptability are commonly cited [52]. Translocation can also be used to reduce human-wildlife conflicts because some interaction between humans and fauna and the resultant retaliatory killings can endanger the populations of these animals (felids, bears, snakes, etc.) [53, 54]. For all these reasons, it is essential to assess effectiveness of translocations in order to aid decision making. However, even before being able to perform concrete quantitative reviews (e.g. meta-analyses) on the efficacy of wildlife translocations, there is an equal need to extensively catalogue all types of wildlife translocation operations in relation to such factors providing a preliminary evidence base or a 'landscape of knowledge', hence the scope of this map.

Although previous overviews exist $[45,51,55,56]$, to our knowledge there are a distinct lack of literature reviews of the systematic-map nature aiming to catalogue the number of different interventions implemented to, from, and within protected areas. We analysed publications dealing with all kinds of animal and plant species translocations, worldwide. The key aims of the systematic map were to identify (1) where all types of translocations take place; (2) what the purposes and motivations are behind translocations; (3) what taxonomic groups are involved across all types of translocations; (4) what the most common direction of movement is in terms of protected areas (and what level of protection they have); (5) what distances are involved for the associated taxonomic groups; (6) how many individuals are translocated; and (7), what types of outcomes are assessed. Lastly, the financial costs of the translocations were summarised if these data were available.

\section{Stakeholder engagement}

Given the mounting evidence on the negative effects of climate change on species viability and ecosystem integrity, there is an emerging consensus within the scientific and policy communities that conservation translocation may be a necessary means to boost declining species' populations, restore ecological processes [25], and assist species migration to favourable habitats [57]. However, more research on translocations and its risks are needed [58]. Making decisions on such a complex subject-as reserve managers may have to do-is an arduous task because there remain uncertainties due to many different programs experiencing variable results [59]. The current work was integrated into the project "Natur'Adapt", a European LIFE programme coordinated by the French Nature Reserves Network (RNF). Among the first actions of this LIFE, several evidence syntheses have been planned, to inform future decision-making by reserve managers. These reviews will help the reserve managers build their adaptation plan, transferring scientific knowledge in an accessible and summarized form. The selection of the evidence synthesis subjects was made in cooperation with RNF, The Natural History Museum (MNHN), and the reserve managers through dialogue and meetings. In particular, reserve managers were asked to propose the most relevant conservation/management measures in the context of climate change, of which they were most expecting information. Then, during the opening meeting of the LIFE program, a workshop was carried out with the reserve managers to select, among all propositions put forward, those that would be definitively chosen for evidence synthesis. Translocation was considered a necessary future conservation action plan in order to help align conservation efforts in protected areas to the challenges associated with climate change, in France and across Europe. A systematic map was subsequently chosen as a central reference tool that reserves managers could use as a systematised log of interventions undertaken to date.

Indeed, before being able to perform concrete quantitative syntheses on the effectiveness of wildlife translocations, RNF requested a comprehensive catalogue of existing literature describing the links between different types of wildlife translocation interventions and the factors that may be important to consider before implementation. Several further meetings were held, (refer to protocol [60] for full details), providing reserve managers the opportunity to contribute to the coding and data extraction decisions/procedures (notably the definition of variables). Following the acceptance of the protocol, further dialogue with managers enabled decisions to be made on the form and content of a practitioner brief, which will provide a summary of key results in an operational manner in order to aid decision-making.

\section{Objective of the review}

The proposed systematic map is intended to provide a thorough overview of the existing literature cataloguing the outcomes of wildlife translocations carried out in the context of protected areas (i.e. translocations where the individuals have been transferred between different protected areas, come from non-protected sites, or relocated within the same reserve). Our 
primary research question was: what is the type, extent, and distribution of existing evidence on the outcomes of such wildlife translocations? The aim of this systematic map was to describe the different types of translocation conservation interventions and several factors that could be important to consider for planning (e.g., IUCN protection category, intervention type, outcomes measured, distances between capture and release sites, and taxonomic groups studied). Also, identifying knowledge gaps and knowledge clusters, which are sufficiently covered by existing studies to allow for full systematic reviewing. The systematic map was based on the following study components (see Table 1).

\section{Methods}

This systematic map followed the detailed methods described in the a priori systematic map protocol [60]. It was performed in strict concordance with the guidelines provided by The Collaboration for Environmental Evidence [61], and conforms to the ROSES reporting standards (see Additional file 1).

\section{Deviations from the protocol}

In the systematic map protocol, we had committed to performing Kappa tests on 10\% of the eligible articles to assess the consistency of the reviewers during the screening process. We were able to respect these samples for titles and abstracts. Unfortunately, due to a lack of time and means, we were only able to perform our full-text Kappa test on $5 \%$ of retained articles.

Regarding the coding step (extraction of the metadata), the systematic map protocol provided, as a first option, an independent coding for each article by two reviewers. But, in case of time constraints, it provided as a second option that an a posteriori cross-check could be carried out with discussion between the coders on potential disagreements. Indeed, due to the lack of project resources, we had to choose this alternative option.

\section{Search for articles Languages}

Only English terms were included in the searches and, from the returned articles, those in either English and French were assessed and read, due to limited resources and the languages understood by the map team.

\section{Search strings}

The following search string was built during a scoping exercise in Web of Science, described in the systematic map protocol [60], for use in bibliographic databases (see section below):
TS $=(($ "protected area $\$$ " OR "protected landscape $\$ "$ OR "protected site\$" OR "receptor site\$" OR "reintroduction site\$" OR "natur* reserve\$" OR "national park\$” OR "regional park\$” OR "national reserve\$” OR "biological reserve\$” OR "biosphere reserve\$" OR "regional reserve\$" OR "wilderness area\$” OR "natural monument\$" OR "management area\$" OR sanctuar*) AND TS=("assisted colonization" OR "assisted population migration" OR "assisted migration" OR "assisted gene flow" OR "managed relocation\$" OR transloc" OR reintroduc* OR reinforc" OR "assisted range expansion\$" OR "assisted long-distance migration\$" OR rewilding OR "wild release")). Search strings for all the databases and searches engines are listed in Additional file 2 .

\section{Bibliographic databases}

Two online bibliographic databases were searched using the search string described above:

- 'Web of science Core Collection' (WOSCC) accessible on the Web of Science platform (Clarivate), using the right access from the MNHN (French National Museum of Natural History). The search covered the entire database (i.e. all the citations indexes: SCI-EXPANDED, SSCI, A\&HCI, CPCI-S, CPCI-SSH, BKCI-S, BKCI-SSH, ESCI and CCREXPANDED). It returned 2322 citations.

- Scopus (Elsevier), using the access from the CNRS (National Centre of Scientific Research). It returned 2563 citations.

For both the databases, the requests were run on 5 August 2020, targeting the topic (TS for WOSCC; TITLE-ABS-KEY for Scopus) and without any restriction (timespan, search area, etc.).

\section{Web-based search engines}

A supplementary retrieval of articles was undertaken using these web-based search engines:

- Google Scholar (https://scholar.google.com/). We used the software programme "Publish or perish (version 6)". Given the conditions of this software (characters limit allowed), we could not use the search string described above and a selection of keywords had to be made (see Additional file 2search strings). The software's use of Boolean characters also differs; as a result, the search string was broken down into 10 separate sub-searches in order to achieve a similar comprehensiveness to WOSCC 
Table 1 Components of the systematic map

\begin{tabular}{|c|c|c|c|}
\hline \multirow{2}{*}{$\begin{array}{l}\text { Population } \\
\text { (P) } \\
\text { Interven- } \\
\text { tion (I) }\end{array}$} & \multicolumn{3}{|c|}{ All plant and animal species of wild or captive source } \\
\hline & $\begin{array}{l}\text { Type of interven- } \\
\text { tions }\end{array}$ & Definition of interventions & \\
\hline & Introduction & $\begin{array}{l}\text { This refers to the intentional manual } \\
\text { transfer/movement and release of an } \\
\text { organism outside of its indigenous } \\
\text { range/historical distribution [13] }\end{array}$ & $\begin{array}{l}\text { (i) Assisted migration: this refers to the } \\
\text { intentional manual transfer/movement } \\
\text { and release outside of the indigenous } \\
\text { range, to primarily avoid extinction of } \\
\text { populations of the focal species [13] }\end{array}$ \\
\hline & & & $\begin{array}{l}\text { (ii) Ecological replacement: this refers } \\
\text { to the intentional manual transfer/ } \\
\text { movement and release of an organism } \\
\text { outside its indigenous range/histori- } \\
\text { cal distribution, to perform a specific } \\
\text { ecological function [13] }\end{array}$ \\
\hline
\end{tabular}

Reintroduction This refers to the intentional manual transfer/movement and release of an organism inside its indigenous range/historical distribution but from which it has disappeared or become extinct locally, regionally, or otherwise. (No conspecifics are present in situ) [13]

Supplementa- This refers to the intentional manual transfer/movement and release of an organtion ism into the existing distribution of a population of conspecifics [13]

\section{Conservation aim of intervention}

This occurs if the persistence of a species in its indigenous range is threatened from current or future impacts than at alternative sites [13]

This is used to re-establish an ecological function lost through extinction; involving the most suitable existing sub-species, or a close relative of the extinct species [13]

The conservation aim is to re-establish a viable population of the focal species within its historical range [13]

The aim is to enhance and reinforce population viability e.g. by increasing population size, or by increasing genetic diversity [13]

Comparator No comparator will be required stricto sensu. Although in certain cases the study design may translate as a time series comparison (before (C) and after translocation)

Outcomes (0) Outcome category Outcome description

Space use Studies measuring all movement/dispersal of translocated individuals. This will include notably home range measurements, or Euclidean distance travelled

Demography Studies outlining the changes in number of individuals, males/females, of the translocated population i.e. population growth overtime

Survival Studies illustrating precisely the proportion of individuals alive or level of mortality since translocation

Reproduction Any impacts on reproduction, expressed by number of young born since translocation, or specifically the survival rate of offspring

Feeding All impacts specifically on diet and feeding of translocated individuals. (Nb. cascade effects will not be included as an outcome)

Behaviour Studies measuring changes in terms of communication (e.g. vocal), social structure, or anti-predator behaviour i.e. stress/ vigilance levels, of translocated individuals

Behaviour Studies measuring changes in terms of communication (e.g. vocal), social structure, or anti-predator behaviour i.e. stress/ vigilance levels, of translocated individuals

Physiology All biological or physiological impacts measured at the molecular, cellular or organic level (e.g. hormone activity)

Context Type of protected areas

$(C)^{a}$

Definitions of protected areas

Strict reserves for the protection of Areas set aside to strictly protect biodiversity where human visitation, use, and impacts are strongly limited [31] nature (la)

Wilderness areas (lb)

Areas that are largely unmodified, retaining their natural character, and free of inappropriate or excessive human use or presence [31]

National Parks (II)

Protected areas of large natural or near natural areas set aside to protect large-scale ecological processes [31]

Natural monuments (III)

Protected areas set aside to protect a specific natural feature in the landscape [31]

Management areas (IV)

Specific protected areas that aim to safeguard a particular species or habitat. Consequently, the management reflects this priority [31]

Protected landscapes (V)

A protected area where humans and nature together over time have produced an area of significant ecological, biological, cultural and scenic value [31]

Protected areas with sustainable Protected areas which conserve ecosystems and habitats together with associated cultural values and tradiuse of natural resources $(\mathrm{VI})$ tional natural resource management and use [31] 
and Scopus. Each sub-search was limited to the first 200 search hits, in line with recommendations [62].

- UK Theses and Dissertations (https://ethos.bl. uk). We used the "Advanced search" mode and five intervention key words: reintroduction OR reinforcement OR introduction OR translocation OR rewilding. We archived the first 200 titles in an excel spreadsheet.

- Conservation Evidence (https://www.conservati onevidence.com/). We searched for primary research papers within Journal's "Advanced search" mode targeting individual studies only with the use of the same five key words: reintroduction, reinforcement, introduction, translocation, rewilding. Only one key word can be used at a time; we thus extracted the first 40 hits per keyword search (200 hits in total).

- US Federal Science database (https://www.science. gov/). We searched all literature using the topic tab "Text", which returns reports, conference papers, and other textual information. A basic string can be used with Boolean characters. Likewise for the retrieval of theses, the string used for this organizational website was: reintroduction OR reinforcement OR introduction OR translocation OR rewilding. The First 200 hits were archived and managed in excel.

Searches on all the web-based search engines were performed on 7 July 2020 (see Additional file 2 for details about search on web-based search engines).

\section{Specialist websites}

On 27 July 2020, we conducted hand searching for relevant articles on the following six specialist websites:

- US Fish and wildlife service (https://www.fws. gov/).

- Office National de la Chasse et de la Faune Sauvage (http://www.oncfs.gouv.fr/).

- IUCN Conservation Planning Specialist Group's document library (http://www.cpsg.org/documentrepository).

- Association of Zoos \& Aquariums (https://www. aza.org/). Including the European Association (https://www.eaza.net/).

- Rewilding Europe (https://rewildingeurope.com/).

These websites do not allow a standardised literature search. Thus, the bibliographic sections of these different websites were manually navigated to look for relevant documents. Indeed, due to time restraints, we restricted our manual research on specialist websites to available documents and reports only. Therefore, we did not include webpages or videos, which are often equally available. As it is commonplace that key method details are too summarised on webpages, we took the decision to only analyse 'downloadable' documents and reports enabling in-depth reading of texts.

\section{Supplementary searches}

A call for literature was conducted via two stakeholders: RNF and EuroParc. Specifically, a request for grey literature (scientific articles excluded) was undertaken through their mailing lists and professional networks. This allowed the mapping team to acquire 42 additional bibliographic documents (including technical reports, syntheses, and Master's theses).

\section{Testing the comprehensiveness of the search results}

A test list of 40 scientific articles was used to assess the comprehensiveness of the search string on literature databases. The test list was composed of relevant scientific articles including a range of conservation translocation interventions, study populations, and publication years thought to be representative of the literature base and appropriate for answering the primary question. The review team identified these articles prior to the mapping process. Of the 40 articles 38 were retrieved by the search string (either in WOS, Google, or Scopus). Firstly, we checked if the search string retrieved articles in WOSCC. If an article was not retrieved by the search string in WOSCC, we checked for its retrieval in Google. If not retrieved in Google, we checked for its retrieval in Scopus. (If an article in question was indeed indexed in WOSCC, we did not check if indexed Scopus.) WOSCC retrieved 32 out of a total of 35 indexed articles. After checking for the remaining articles in Google and Scopus, an additional 2 were retrieved by Google, and 4 by Scopus (38 in total). Thus, the combined sub-comprehensiveness was $100 \%(38 / 38)$ if not including the 2 articles that were not indexed at all. But, the global comprehensiveness of our search strategy was 95\% (38/40) as 2 articles not indexed in either WOSCC nor Scopus were not found either by Google. More details (including the two unretrieved articles) are provided in Additional file 3.

\section{Article screening and study eligibility criteria Screening process}

All citations were extracted and archived in a bespoke excel spreadsheet. Screening and management of 
bibliographic information was subsequently undertaken in excel. Three distinct screening stages were carried out successively for all articles (including articles coming from the call for literature and the specialist websites): (1) titles, (2) abstracts, (3) full-texts. Articles found by means of hand searching specialist websites were only assessed at the full-text stage. During the title and abstract screening process, in case of any doubt over the presence of a relevant inclusion criterion (or if the information was absent) the article was passed, by default, to the next screening stage.

The three screening stages were performed by two reviewers (JL and RS). In order to check that consistent and repeatable decisions were made, adherence to the eligibility criteria was assessed between the two reviewers using a Kappa test at the start of each screening stage. To that end, a set of articles was randomly selected: $10 \%$ for titles after duplicates were removed (463/4632), $10 \%$ of retained abstracts (193/1786), and $5 \%$ of retained full texts (59/1182). Kappa statistics were calculated at each stage, scores greater than 0.7 were deemed successful i.e. agreement attained. Any remaining disagreements were discussed and resolved between the two reviewers before commencing screening of literature. During the screening process, reviewers did not screen any articles that they had authored themselves.

\section{Eligibility criteria}

Article eligibility was based on the list of PICO criteria detailed in Table 2, with no deviation from the a priori systematic map protocol.

No study design types were excluded during the screening stages. This was done in order to achieve a comprehensive overview of the different kind of evidence existing on wildlife translocations in protected areas.

Regarding language, we included only publications written in English or in French. This criterion was considered at the full-text screening stage. This meant that if an article had an abstract written in a language other than French or English, it was still not excluded and it was transferred to the full-text screening stage.

No publication types (e.g. books, conference proceedings, peer-reviewed journal articles, theses, technical reports, etc.) nor contents (e.g. field studies, reviews, meta-analyses, discussion papers, etc.) were excluded during the screening process. However, reviews and syntheses (e.g. systematic reviews and maps, and metaanalyses) were not coded because these evidence syntheses often summarise findings across an overlapping set of multiple articles.

\section{Study validity assessment}

No critical appraisal was undertaken on retained articles because the intention of the map was not to examine the robustness of the study designs. Critical appraisals of study validity is not essential for systematic maps but we coded study design to provide a preliminary overview of internal validity [61].

\section{Data coding strategy}

Metadata were coded for all the articles passing the three screening stages. For this coding, the "study unit" was defined as "a unique translocation operation". Thus, if multiple studies were reported within one article they were entered as an independent line in the systematic map database. In addition, one translocation operation was distinguished from another if the populations were different and/or if release site localities were unique geographical locations (cf. "Data mapping method").

The key variables of interest were coded in terms of: (1) bibliographic information (the document type, and type of bibliographic content), (2) study characteristics (the study country, release and capture coordinates, climate zones of capture and release sites, distance $(\mathrm{km})$ between each, source and destination e.g. captive site to wild release, protected area context and IUCN protection category, the release site's biome, and programme's motive, period of time, costs), (3) population characteristics (the taxonomic group, sample size, age of released individuals), (4) intervention characteristics (whether a reintroduction, supplementation, introduction, or a combination of two), and (5) outcome characteristics (whether related to physiology, feeding, behaviour, space use, reproduction, survival, demography, or genetics). Full details are given in the systematic map protocol, with no deviations (a codebook is provided along with example coding formats). When the data was not sufficiently detailed or simply unknown, we coded as such (using "Unknown" when necessary).

The coding stage was performed by three coders (JL, RS and HM) who shared the eligible articles between them and coded all variables for their respective samples. Due to resource and time limitations, an independent dual coding of the entire database was indeed not feasible. However, in order to guarantee that information was coded and extracted in a consistent and repeatable way, a four-step process was undertaken.

- Step 1 "discussion session": discussions were held between the three coders, before the extraction of metadata commenced, to ensure any doubts prior to coding were clarified: JL gave thorough explana- 
tions regarding coding rules to RS and $\mathrm{HM}$ for all the characteristics of the Map.

- Step 2 "practice and re-discussion session": immediately following the first discussion session, 5 articles were randomly selected to be practice coded by RS and HM. This coding step was monitored by JL who gave further explanations to the two other coders in cases of doubt. Indeed, any disagreements were re-discussed. This was a pre-pilot testing phase, purely for practice purposes.

- Step 3 "pilot-testing": a pilot extraction phase was undertaken by JL, RS, and HM on an identical sample of 10 articles. This was undertaken to ensure all characteristics were coded consistently by all three reviewers, discussing any potential disagreements. Before starting the actual coding process, this pilottesting step was repeated until no disagreements occurred. We required two tries until all coded characteristics were homogenous. 20 articles were therefore coded in total.

- Step 4 "post-coding crosscheck": once coding had been completed, an a posteriori crosscheck was carried out by JL on the entire database to identify any errors and homogenize all coded terminology. All disagreements were discussed until a consensus was reached for the concerned articles. (N.B., during the coding process the reviewers were in contact and could question each other in case of any doubt).

\section{Data mapping method}

All the coded metadata for all the studies were included in a systematic map database: a bespoke
Microsoft excel spreadsheet. By cross-tabulating the data, summary figures and tables were produced for this Map report to identify knowledge gaps (i.e., subtopics requiring further primary research) and knowledge clusters (i.e., subtopics that are sufficiently covered by existing studies to allow for full systematic reviewing). The distribution and frequency of translocation operations was presented with heatmaps, or geographical maps illustrating the number of interventions by country. Based on these results, recommendations were made on priorities for policy makers, practitioners, and research.

Because our aim was to not only code the literature base in terms of number of publications (hereafter referred to as "Bibliometric synthesis") but also extract information on specific translocation events within these retained publications (hereafter referred to as "Translocation synthesis"), we underwent a three-step mapping process:

i. Firstly, we permitted a coding of "unclear context" due to the complexity of many publications. If publications did not explicitly describe the name of a protected area in the given translocation event but gave sufficient information to assume our PICO criteria were otherwise respected, during the screening process, these articles were coded but consequently not included in the systematic database. A brief narrative summary is given without tables (cf. "Unclear cases" section, in Review findings).

Table 2 Inclusion/exclusion criteria for the three-stage screening process

\footnotetext{
Eligible population(s) All terrestrial, marine, or aquatic plant or animal populations from any country across the globe that were of wild or captive source. Wild populations included any free-ranging species from natural environments; not domesticated or cultivated. Captive populations included species born in captive setting (e.g. zoos, nurseries, or breeding pens)

Eligible intervention(s) All conservation-based translocation interventions occurring either (1) between two different protected areas; (2) from a non-protected area to a protected area; (3) from a protected area to a non-protected; or (4) within the same protected area where the aim is improving the viability and persistence of the translocated population (i.e. reintroduction, supplementation, or assisted migration (see Table 1 for definitions). Ecological replacement was also included as an eligible intervention where the goal is to re-establish an ecological function lost through extinction, which involved the translocation of the most suitable existing sub-species, or a close relative of the extinct species

Eligible comparator(s) With regard to a systematic map, comparator was not a screening criterion

Eligible outcome(s) Any outcome-related effects on the translocated populations. This included (1) Space use i.e. studies measuring all movement/ dispersal of translocated individuals, notably home range measurements or Euclidean distance travelled. (2) Demography i.e. studies outlining the changes in number of individuals (males and/or females) of the translocated population. (3) Survival i.e. studies illustrating precisely the proportion of individuals alive or level of mortality since translocation. (4) Reproduction i.e. number of young born since translocation, or specifically the survival rate of offspring. (5) Feeding i.e. all effects specifically on diet and feeding of translocated individuals. (6) Behaviour i.e. studies measuring changes in terms of communication (e.g. vocal), social structure, or anti-predator behaviour e.g. stress/vigilance levels, of translocated individuals. (7) Genetics i.e. studies relating to the genetic structure of the translocated species. Finally, (8) Physiology i.e. biological or physiological impacts measured at the molecular, cellular or organic level of translocated population (e.g. hormone activity)
} 
We divided the Map's narrative synthesis into two parts, a "Bibliometric synthesis" and a "Translocation synthesis".

ii. Concerning the Bibliometric synthesis: this part of the synthesis included all retained literature coded by document type i.e. one line in the Excel datasheet corresponding to a single publication (i.e. either a Book, conference object, journal article, report, technical documentation, or thesis). For each document type, we coded bibliographic content (i.e. either a discussion paper, modelling, overview, review, or study). Study in this instance was regarded as a field-based study where data was acquired in the field. Equally, "programme motivation" was coded except for reviews and overviews because these documents may themselves summarise a number of operations with a number of different motives. Thus, reviews and "metapopulation management" (one of six coded programme motivations) articles were coded only for the bibliometric variables mentioned above. Concerning the latter, these were considered inappropriate and too time consuming to code in the translocation synthesis as the same individuals may be repeatedly transferred back-and-forth between fenced reserves in order to cope with the particular problem of lack of gene flow between enclosed populations.

iii. Concerning the "Translocation synthesis": from all the remaining publications this part of the synthesis involved coding the specific translocation events consistent with the IUCN definitions. Two key variables (method and location) were used as cut-offs to define a study unit [63], i.e. a translocation. Therefore, a translocation was coded as a unique data line in the Excel datasheet if: (1) a different species was translocated, and/or (2) the release site was a unique geographical location. If the same species were translocated to clearly different release sites, these were presumed not to be the same individuals under movement thus coded as unique data entries. Time duration was not considered as a cut-off when distinguishing translocations events. Consequently, some translocation interventions, coded as for example, "Reintroduction + supplementation" may have particularly long time periods if the supplementation part of the intervention followed the initial reintroduction several years later.

iv. From this, a search for linked data (cf. "Linked data" section) eliminated duplicated translocations from the evidence base.

\section{Linked data}

Once all the studies had been coded, we undertook a search for linked data. This was done in order to locate articles, published by either the same or different authors, referring to the same translocation event. Indeed, we wanted our Map to be able to isolate single translocation events, without duplicates i.e. multiple publications referring to the same event. Therefore, if: (i) the same species, (ii) the same capture site, (iii) the same release site, (iv) the same intervention type, (v) the same number of individuals reported, and (vi) for the same translocation period, we subsequently tagged such translocations as "linked data". We assumed that if these 6 factors matched, the likelihood was high that two different publications were reporting the same transfer of individuals. When a single translocation was coded multiple times, we retained the publication providing the more detailed description. In the case where a single event was described in a thesis and a corresponding scientific article, we retained the peerreviewed article.

\section{Review findings \\ Literature searches and screening process}

The ROSES flow diagram for systematic maps illustrates the screening process (Fig. 1). Our literature search yielded 4981 hits from WOSCC and Scopus. A further 1373 hits from various other sources were retrieved: Google Scholar, organisational websites, a grey literature call and hand search on specialist websites. This resulted in a total of 6354 records and 4617 unique records after removal of duplicates. At title screening, 2841 titles were excluded, leaving 1776 for abstract screening. During the abstract screening stage, 510 references were excluded, leaving 1266 for full-text screening. However, 78 articles (6.2\%) were unobtainable (Additional file 4) i.e. authors were not able to locate the articles in question through the internet or French National history Museum or the CNRS (National Scientific Research Centre) subscriptions. Thus, 1188 articles were submitted to full-text screening. A total of 498 articles were rejected at full-text mostly due to irrelevant interventions (i.e., articles in question did not describe a translocation operation in the context of a protected areas), irrelevant outcomes (i.e., article did not evaluate effects on translocated population), or irrelevant population (i.e., article reported data for invasive species, or species manually relocated for non-conservation purposes such as hunting). Finally, a total of 690 publications were accepted for coding [Additional file 6 sheet "Full List of articles (690)"]. Additional file 5 outlines all information on the three screening stages 
(inclusion/exclusion screening process, dates, screeners, reasons for exclusion, etc.) (sheet "List of all articles"). The list of articles excluded at full-text stage along with reasons for their exclusion can be found more easily in a specific sheet of the Additional file 5 (sheet "List of excluded articles FT").

From the 690 articles accepted as eligible for the review after the three screening stages,

i. 42 publications (65 translocations) were coded as "unclear context" not sufficiently describing the role of the protected area in the given translocation event despite these articles meeting our PICO during the screening process. These articles were consequently not included in the systematic database but in a specific Additional file 6 (sheet "Unclear contexts") and described briefly in "Unclear cases" section in Review findings.

ii. 58 linked translocations (35 publications) were detected and eliminated from both parts of the narrative synthesis (see Additional file 7, sheet "Linked data").

iii. Concerning the Bibliometric synthesis [Additional file 7-sheet "4. Full database (613)"]: 613 publications in all were coded for the following bibliometric variables: document type, bibliographic content, and programme motivation). Except programme motivation was not coded for 90 reviews (cf. "Data mapping method").

iv. Concerning the "Translocation synthesis": 841 translocations (i.e., intentional movements of any organism from one site to another) were fully coded in respect to all descriptors [see Additional file 7, sheet "Translocation database (498)"]. These translocation events were extracted from 498 different publications (having not extracted translocation events from 115 publications: 90 review articles and 25 "metapopulation management" articles).

\section{Bibliometric synthesis}

The total number of publications summarised in this section is 613-after eliminating "unclear contexts" and "linked data"-including reviews, programme motivation, and translocation studies. (cf. sheet 4 "Full database (613)" in Additional file 7).

\section{Publication type and content}

Figure 2 shows the distribution of publication types. The systematic map is mainly composed of journal articles $(85 \%)$. The second highest proportion $(5 \%)$ of publication type in the systematic map are book chapters.
$\mathrm{Ph} . \mathrm{D}$. theses accounted for $3 \%$ of included publications. This equated to 15 different theses reporting translocations in the context of protected areas. Figure 3, shows the distribution of publication contents. Indeed, the majority of translocations in the contexts of protected areas were published from field studies i.e. data acquired from on-the-ground studies. Then, reviews (9\%), and then other (8\%, comprising of various publication formats such as short communications). Overviews made up $5 \%$ of the systematic map, followed by modelling publications (3\%) where field data was not necessarily collected.

\section{Publication motivation}

In terms of programme motivation by publication (Fig. 4) - not including the 90 review papers-the vast majority of articles published documented aims to restore and improve the conservation status of the focal species: 353 publications in total, which represented $57 \%$ of all publications. Secondly, 9\% (56) of publications did not detail the motivations for translocating wildlife ("Unknown"). $8 \%$ of publications were for documenting a trial transfer prior to a translocation operation. 25 publications were specifically on metapopulation management, 18 on wild-human conflicts, 18 on wildlife rescue, with only a very small number of articles on rewilding (1\%).

\section{Publications by year}

Publication dates ranged from 1969 to 2020, with the majority after 1998 (93\%) (Fig. 5). The period 1969 to 1997 equated to 7\% of publications. Grey literature made up a larger proportion of the total studies in more recent years. Indeed, the grey literature included in the systematic map were all published from 1994 onwards.

\section{Translocation synthesis}

The number of publications summarised is 498, from which 841 unique translocations were coded. (cf. sheet 5 "Translocation synthesis" in Additional file 7). 115 publications (Reviews and "metapopulation management" papers) are excluded from the translocation synthesis section.

\section{Translocation motivation: reasons for moving wildlife}

We coded 622 translocations, equating to $78 \%$ of all coded interventions in the evidence base as undertaken in order to improve a focal species' status. Second to conservation purposes, were wildlife rescue operations, this equated to 58 of all translocations carried out in the context of protected areas. Surprisingly 56 translocations comprised of trial or experimental transfers of wildlife to protected areas pre-dating conservation 
ROSES Flow Diagram for Systematic Maps. Version 1.0



Fig. 1 ROSES flow diagram for systematic maps, outlining the overall screening and organisation process

programmes. Human-wildlife rescue operations accounted for 33 translocations, unsurprisingly only animals are concerned, of which 17 transfers did not document if individuals were released into resident populations or not (Table 3). Regarding rewilding, which was considered in the context of reintroducing a species to restore lost ecological functions, equated to only 8 translocations (4 in Argentina, 2 in Brazil and 2 in Germany), and in each case the relocation of a mammal. One study, in Brazil, aimed at reintroducing the red-humped agouti and the brown howler monkey, in Tijuca National Park, Rio de Janeiro; two species that are important seed dispersers, which may be particularly effective at restoring such ecological processes [64]. Finally, 64 translocations had completely 
unknown motives, even if their intervention type was detailed (Table 3).

\section{Translocations by year}

In terms of actual translocations by year (Fig. 6), we can observe a similar trend to that of Fig. 5. Over time, the number of translocation operations have accelerated. Overall, from 1997 to 2020, on average 22.6( \pm 20.9$)$ translocations (all combined) per year were undertaken. But since 2018, an average of 54 per year have been published. From the current evidence base, the year with the highest number of published translocations was that of 2018 (85/841). Further still, only 6\% of coded translocations were undertaken before 1997 . This increase in research output may be an indirect response to the increasing pressures currently facing many animal and plant populations [65], in that in the number of performed conservation translocations are increasing because it is seen as a viable way of enhancing the resilience of threatened species $[25,27,66]$, and thus publications have increased by consequence.

\section{Study locations and climate zones}

Translocations included in the systematic map spanned the globe (Fig. 7). Most translocations were performed in North America, Oceania, and Europe. There was a clear lack of information on translocations in Northern Africa and the Sahel region, and Central Asia. Of the 68 included countries, the most translocations were undertaken in the USA (22\%), Australia (16\%), New Zealand (10\%), and Canada (4\%). In accordance with this geographical distribution, the majority of translocations were released in oceanic/maritime climates (Cfb: 234), followed by warm temperate climate (Cfa: 84), Tropical savanna climate (Aw: 65), humid continental climates (Dfb: 59), desert or arid climate (BWh: 50), equatorial climate (Af: 40), and semi-arid climates (BSk: 37) (Figs. 8 and 9). Less than half of translocations gave sufficient information in order to code the capture and release site climates (44\%). Of the known climates zones (358 translocations), 11\% of translocations changed climate zones between capture and release sites.

\section{Study population: which taxonomic groups are translocated?}

Translocations that were included in the systematic map mainly involved animal species (686). Although, 148 translocations of plants were also included, and 7 translocations of fungi. Of the animal translocations, mammals were the most translocated group (Fig. 10), almost 400 (equating to 56\%) of reported translocations between 1969 and 2020 from 45 different taxonomic families, and 158 different species (Additional file 7). Over 170 (25\%) translocations involved birds, followed by reptiles (42), fishes (28), insects (21), and amphibians (15 translocations). From mammals, the most commonly translocated taxonomic orders were

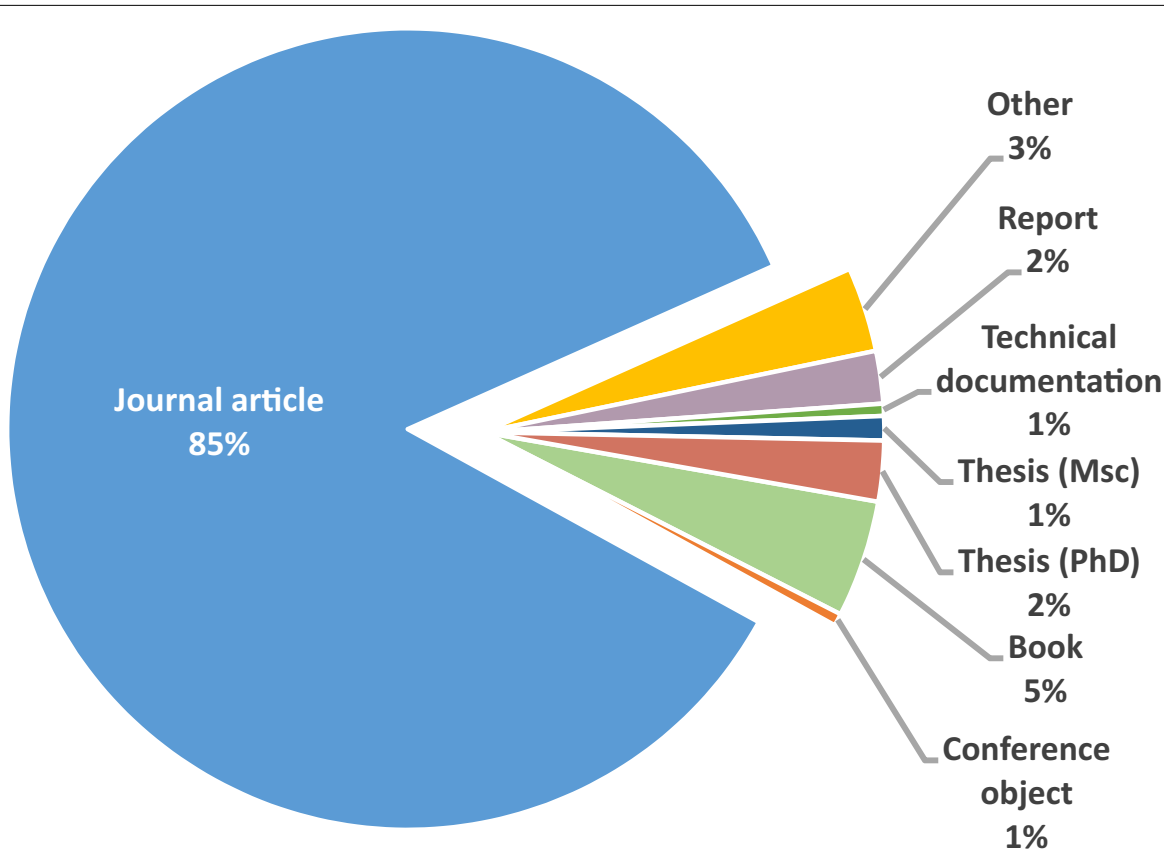

Fig. 2 Proportion of publication types 


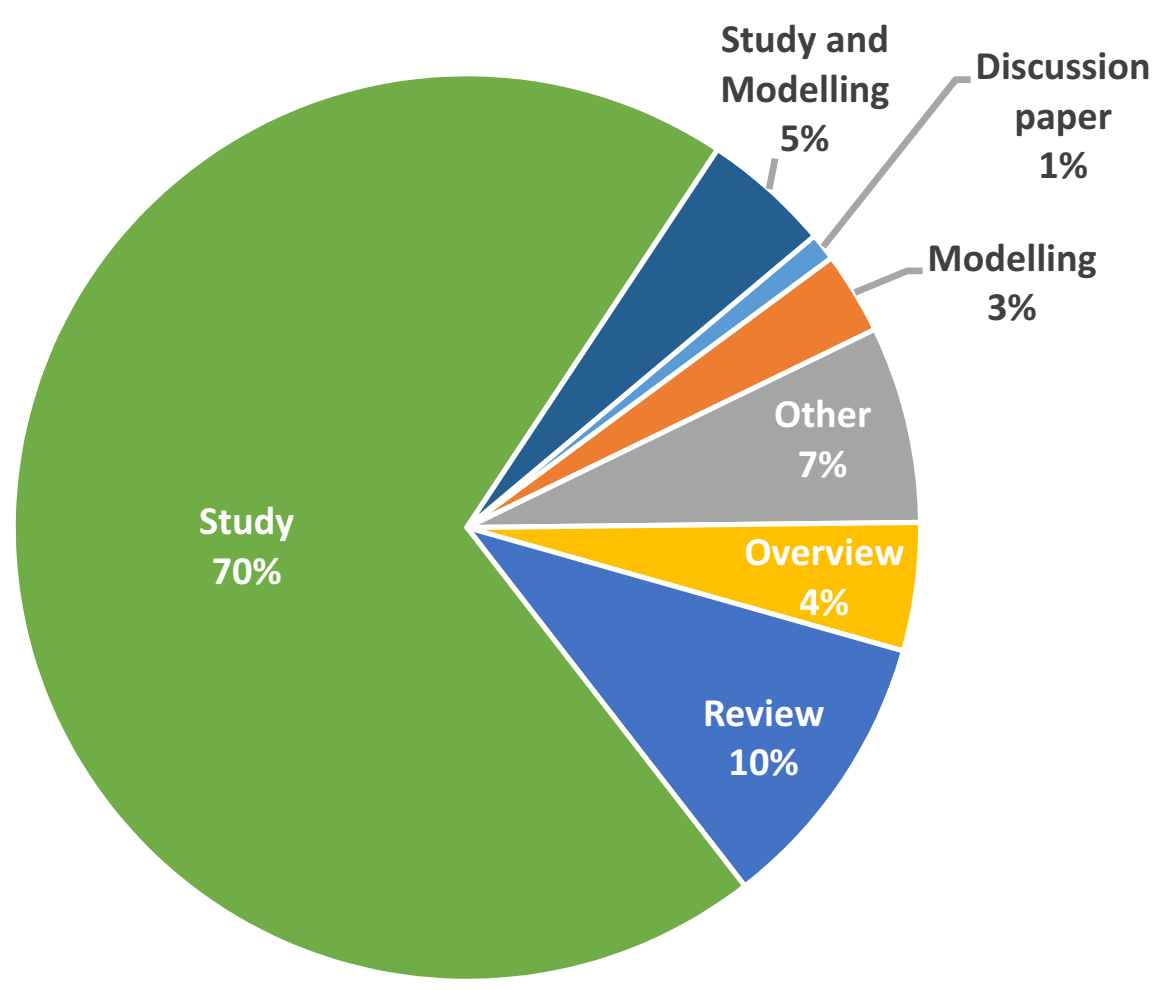

Fig. 3 Proportion of publication contents

Artiodactyla (of which Bovidae, and Cervidae were the most translocated families), Carnivora (of which Canidae and Felidae were the most translocated), Perissodactyla (of which Equidae were most transferred), Diprotodontia (of which Macropodidae), Primates (of which Hominidae), and Rodentia (of which Castoridae was the most relocated). Although marine fauna are also catalogued-Bivalvia, Anthozoa, and Hexanauplia-it would appear that they receive much less attention (Fig. 10). Several plant groups were also translocated (Fig. 11). However, a large bias towards Magnoliopsida is evident, followed by Liliopsida, and Lecanoromycetes. Among translocated Magnoliopsida, Asteraceae were by far the most translocated family. However, a distinct lack of literature concerning non-vascular plants such as bryophytes is highlighted. These knowledge gaps are likely to be associated with the complexity of transferring such taxa. The number of individuals translocated, by age class and taxonomic groups, are provided in Table 4 for Animalia and Table 5 for Flora, for all studies and in average ( \pm standard deviation).

\section{Study interventions: what type of translocations exist, how many individuals are translocated, to where, and over what distances?}

Tables 6 and 7 illustrate the distribution of the number of translocation operations by intervention type, taxonomic class and age at release, for animals and plants/ fungi respectively. Concerning animal translocations (Table 6), 686 were coded in total. 12 different taxonomic classes (332 species) were subject to conservation translocations. The most common intervention was that of "reintroduction + supplementation" (176) i.e. a founder group of a species previously extinct or extirpated reintroduced into its historical range and later reinforced. 158 translocations were of one-off reintroductions (the founder group not being reinforced at a later date) and supplementations. Note that 182 interventions were coded as "Unknown" as information was lacking in their methods. The most translocated taxonomic group were mammals and birds. Of these translocations, adults only or a combination of adults and juveniles was most often the chosen strategy. For instance, adults were transferred alone in 104 

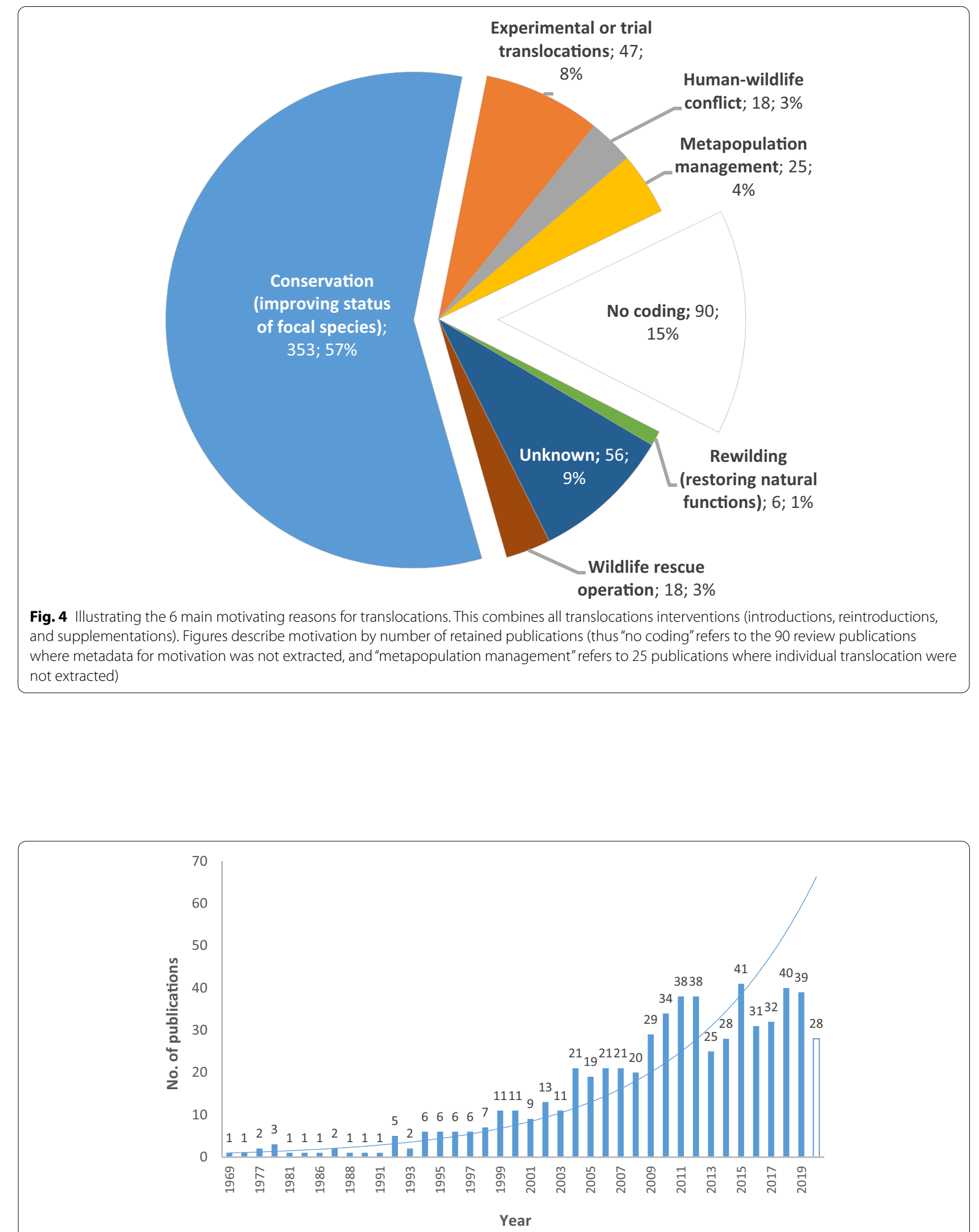

Fig. 5 Number of translocation-related publications per year 
Table 3 Heat-map showing the distribution of the number of translocation operations in terms of programme motivation and taxonomic kingdom. Conservation $=$ any attempt to restore or improve the status of the translocated species; Experimental or trial $=a$ trial relocation prior to the main event; Human-wildlife conflict $=$ any interaction between humans and fauna resulting in the relocation of the individual(s) in question; Rewilding = reintroduction or introduction to restore a lost ecological function; Wildlife rescue $=$ a relocation in order to save the individuals from human activity; Unknown $=$ no information (or not detailed enough) provided by the authors to class motive

\begin{tabular}{|c|c|c|c|c|c|c|c|}
\hline \multirow[t]{2}{*}{ Taxonomic kingdom X Programme motivation } & \multicolumn{7}{|c|}{ Intervention type } \\
\hline & Intro+suppl & Introduction & Reintro+suppl & Reintroduction & Supplementation & Unknown & Total \\
\hline Animalia & 6 & 6 & 176 & 158 & 158 & 182 & 686 \\
\hline Conservation (improving status of focal species) & 6 & 4 & 158 & 123 & 110 & 88 & 489 \\
\hline Experimental or trial translocations & & 1 & 4 & 12 & 13 & 16 & 46 \\
\hline Human-wildlife conflict & & & & 5 & 11 & 17 & 33 \\
\hline Rewilding (restoring natural functions) & & & 3 & 3 & & 2 & 8 \\
\hline Unknown & & 1 & 9 & 11 & 9 & 33 & 63 \\
\hline Wildlife rescue operation & & & 2 & 4 & 15 & 26 & 47 \\
\hline Fungi & & & & 4 & 3 & & 7 \\
\hline Wildlife rescue operation & & & & 4 & 3 & & 7 \\
\hline Plantae & & 4 & 10 & 11 & 41 & 82 & 148 \\
\hline Conservation (improving status of focal species) & & 3 & 10 & 9 & 39 & 72 & 133 \\
\hline Experimental or trial translocations & & 1 & & 2 & 2 & 5 & 10 \\
\hline Unknown & & & & & & 1 & 1 \\
\hline Wildlife rescue operation & & & & & & 4 & 4 \\
\hline Total & 6 & 10 & 186 & 173 & 202 & 264 & 841 \\
\hline
\end{tabular}

"Intro + suppl": the movement of individuals to a habitat outside of their historical range, and subsequently followed up by a supplementation event Introduction: a one-off transfer of individuals to a habitat outside of their historical range

"Reintro + suppl": the movement of individuals that were otherwise extinct or extirpated to a habitat within their known historical range, and subsequently followed-up by a supplementation event

Reintroduction: a one-off transfer of individuals that were otherwise extinct or extirpated to a habitat within their historical range

Supplementation: a one-off transfer of individuals to reinforce an existing resident population

Unknown: refers to all movements that were not detailed sufficiently by the authors in order to code the type of intervention with high confidence

N.B., white space equates to no available data. Red colours equate to a few number of translocations, green colours represent a greater number

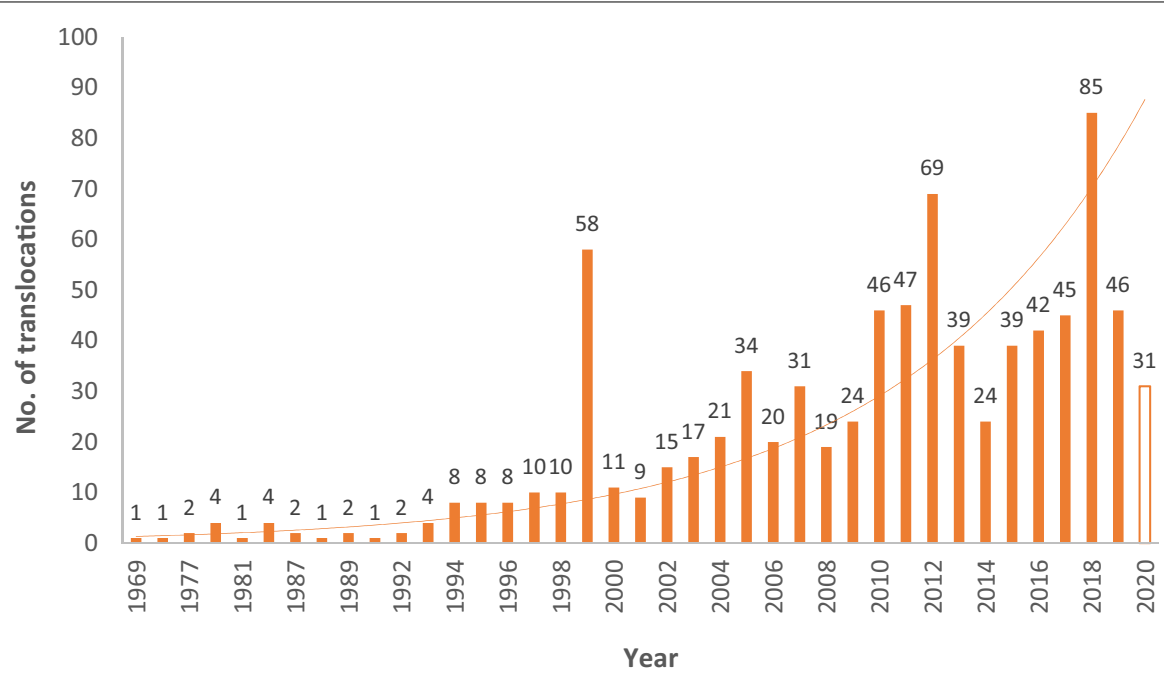

Fig. 6 Number of translocations per year 


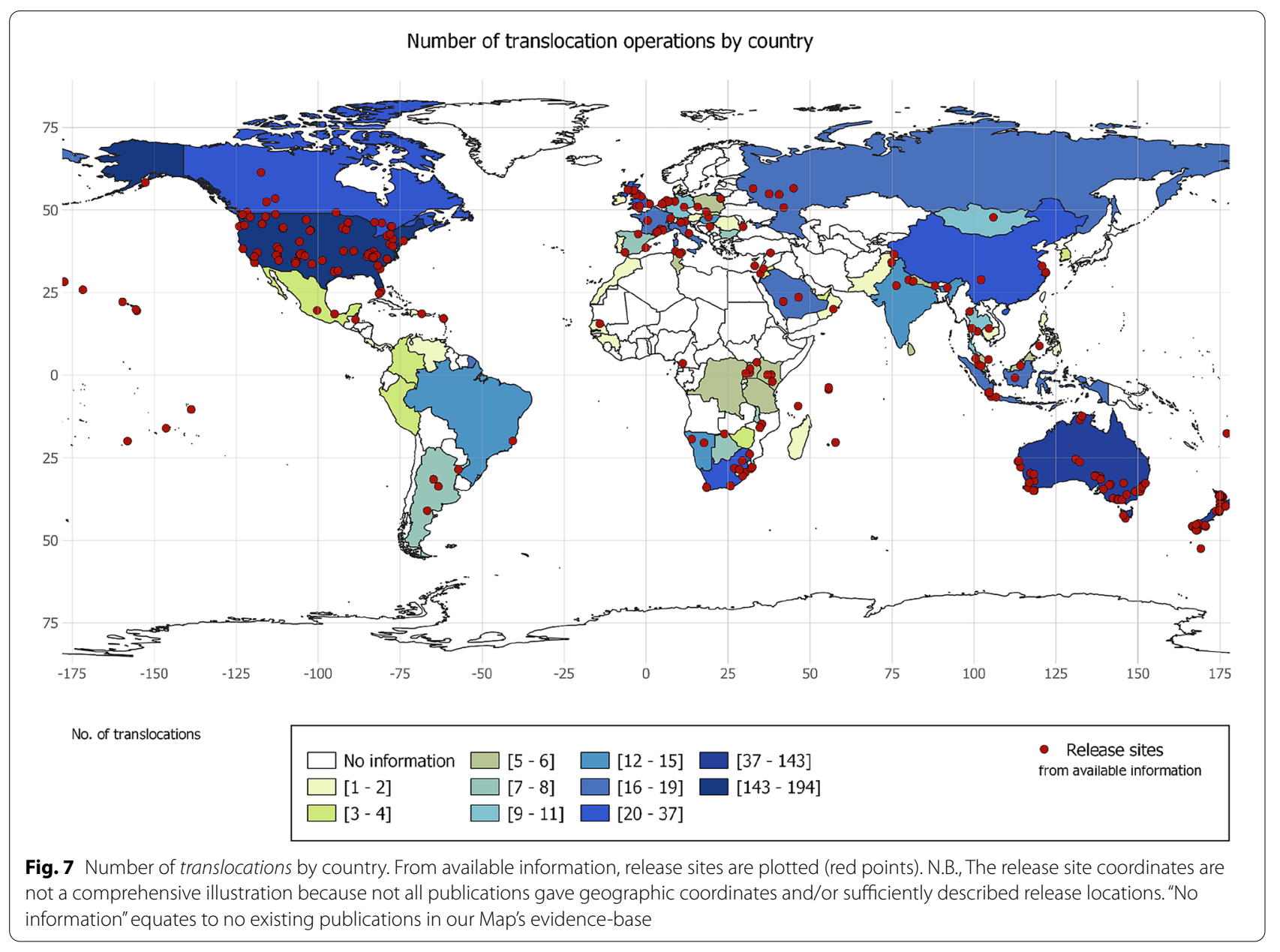

mammal translocation operations vs. 10 translocations where only juveniles were transferred. The least translocated groups were marine taxa, the logistical complexity of such interventions and the specialised equipment such as protective cages [69] needed to increase the chances of success likely, to some extent, explain the lack of literature.

Concerning translocation of plants or fungi (Table 7), 155 translocations, spanning at least 5 different taxonomic groups and 1 fungi taxon in total were documented. The most common intervention type was "supplementation" (44). However, similarly to animal translocations, a large number were uncodable interventions arose due to a lack of information in methods (82). A diversity of plant development stages were translocated. However, contrary to animal translocation, a single development stage (i.e. 'age group') was most commonly selected for translocation. For instance, concerning Magnoliopsida, only one translocation operation attempted to transfer adult plants, seedlings and seeds vs. 23 operations which chose to transfer seeds only.

Further, in terms of the number of individuals transferred per translocation, Tables 4 and 5 summarise this profuse information across the years (1969-2020) in terms of age by taxonomic groups, respectively for animals and plants/fungi. Indeed, concerning animal translocations, over time the number of individuals involved in mammal translocations has been far higher than other taxonomic groups ( $>71,000$ individuals translocated since 1969). Indeed, the average number of individuals transferred per translocation was 529, with a median number of individuals transferred per translocation equating to 20. Interestingly, concerning amphibians, few translocations (15) have been carried out, but large numbers of individuals $(17,801)$ were used across operations. Indeed, it is often the case that large numbers of amphibians are needed to ensure that a viable proportion of the founder population persists [70]. 


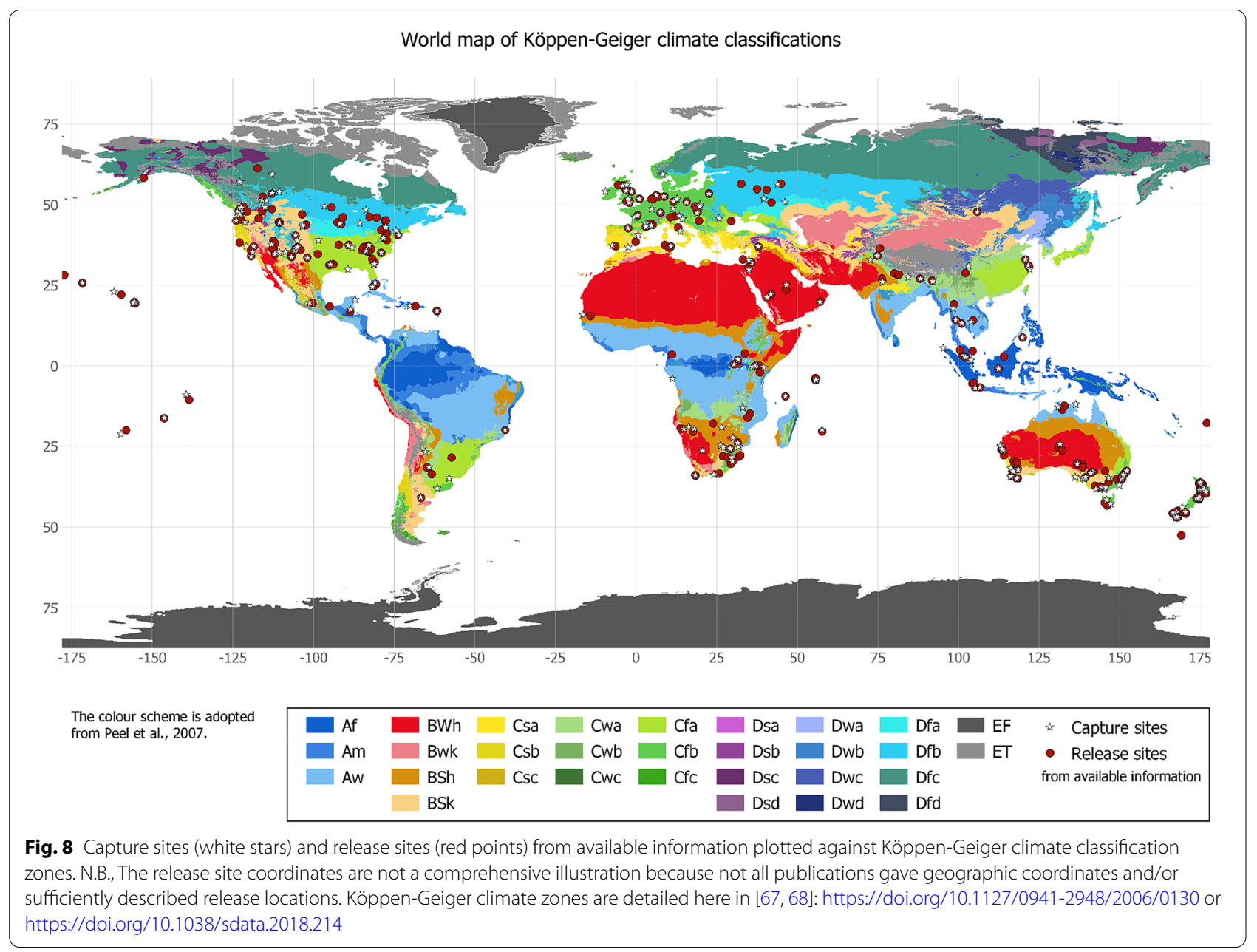

Regarding plant translocations, the highest number of individuals per translocation operation was highest for Magnoliopsida sp. followed by Pinopsida, and then Liliopsida. Interestingly 7 translocations attempted the transfer of thallus fragments of fungi groups (Lecanoromycetes). Concerning Magnoliopsida translocations, the median number of seeds transferred per translocation was $>3000$, where as if adult plants only were chosen for transfer, the median number was 35 per translocation.

In terms of direction of transfer (Fig. 12), the majority (592 translocations) involved a transfer of individuals from non-protected sites to protected sites (illustrated by the "To" category, in Fig. 12). However, of these transfers, 64 had unknown source sites. Secondly, 196 transfers of species were from one protected area to another ("From-To"), 47 translocations occurred within the same protected area ("Within same"), and in 27 rare cases, species were translocated from a protected area and release into non protected sites ("From").
Concerning translocated animals only from nonprotected to protected sites ("To"), 204 of these translocations included the procuration of individuals from either captive or breeding sites subsequently released into protected wild areas. 209 involved the transfer of animals from wild sites to another wild site. Furthermore, these translocations had diverse motives from rescue operations and human-wildlife conflicts, to pure conservation purposes. In two specific examples, a conservation-motivated reintroduction of Ursus arctos, where ten adults were transferred from the "Slovenian alps" to Adamello Brenta Nature Park in Italy [71] was coded as wild site to wild site. In another example of a conservation-orientated reintroduction, 43 passerine birds were transferred from a wild site (verified by given coordinates) to Mulligans Flat Nature Reserve in Australia [72].

Concerning habitat protection, of animal translocations, 20 (13 mammals, 4 insects, 3 birds) were known to be translocated to a protected area with a lower IUCN protected status than the source site, according 


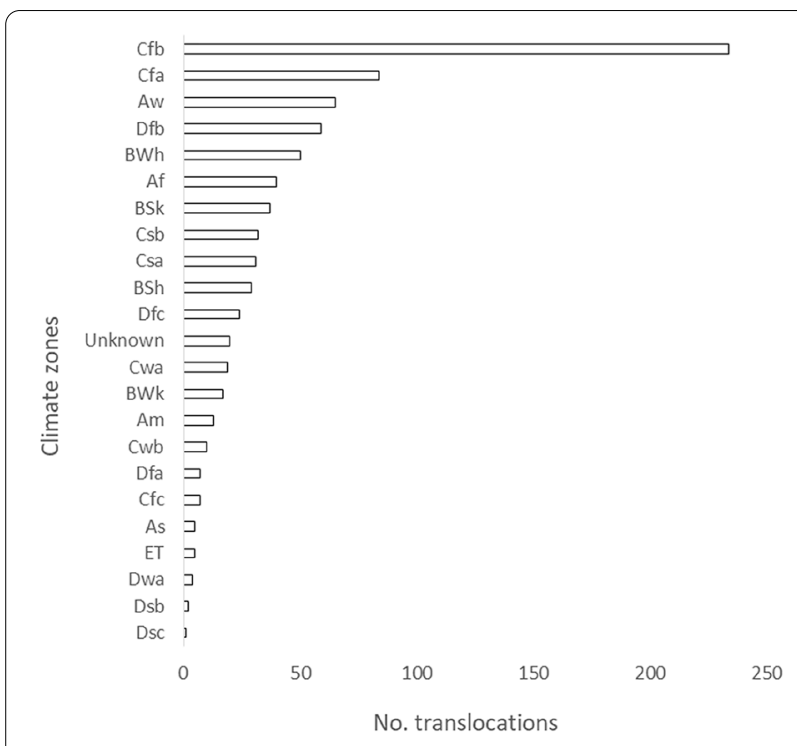

Fig. 9 Number of translocation release sites by climate zone. Cfb: temperate without dry season, warm summer (oceanic climate); Cfa: temperate without dry season, hot summer (humid subtropical climate); Aw: equatorial savannah with dry winter; Dfb: snow climate without dry season (humid continental climate); BWh: hot desert climate; Af: equatorial rainforest, fully humid; BSk: cold semi-arid climates; Csb: temperate with dry summer (cool-summer Mediterranean climate); Csa: temperate with dry summer (hot-summer Mediterranean climate); BSh: Arid hot climates (steppe); Dfc: cold without dry season cold-summer (sub-arctic climate); Cwa: warm temperate climate with dry winter Hot summer (humid subtropical climate); BWk: cold desert climates; Am: equatorial monsoon; Cwb: temperate dry winter warm summer (subtropical highland climate); Dfa: Cold Without dry season Hot summer (humid continental climate); (fc: temperate without dry season, cold summer (oceanic climate); As: equatorial savannah with dry summer; ET: tundra climates; Dwa: cold dry winter hot summer (humid continental climate); Dsb: snow climate with dry-warm summer (humid continental climate); Dsc: snow climate with dry, cold summer (sub-Arctic climate)

to Protected Planet (https://www.protectedplanet.net/ en). In one instance [73], this involved the relocation of 201 Cervus canadensis from Elk island, Alberta (IUCN protection status: II) to a protected landscape (V) over $4000 \mathrm{~km}$ away: the "Tennessee Cumberland mountains". In another [74], 687 Deinacrida mahoenui were transferred from an "scientific reserve" (Ia) to a "scenic reserve" (III), in New Zealand. Comparatively, 38 species were moved to a protected area with a higher protection status. 62 translocations did not experience change in protection status. For 567 translocations of animal species, the protection status' were not reported thus protection status change was Unknown. Concerning the 155 plants and fungi translocations, very little information was reported in respect to protection status: six translocations where no protection status change occurred. The rest of the events were coded as Unknown.

Concerning distances, the map team were able to code up to 358 translocations where geographic coordinates were retrievable for both capture and release sites (representing approximately a third of the "translocation synthesis"). Additional file 8 shows the methods used to calculate distances for these translocations. Indeed, we used the standard Mercator projection. A diverse number of distances are evident for animal translocations. Indeed, the majority of cases were short distance translocations i.e. 0-100 km. However, we can also observe that 54 animal translocations carried out involved distances of over a $1000 \mathrm{~km}$ (Fig. 13). Concerning plants, only 3 translocations involved distances greater than $100 \mathrm{~km}$.

\section{Study outcomes: which impacts are measured?}

Reported outcome measures largely concentrated on: space use, survival, demography, reproduction, feeding, behavior, genetics, and physiology (Fig. 14). Outcome metrics related mostly to the survival of individuals translocated (367). Secondly, space use was largely studied in order to determine all movement/dispersal of translocated individuals. This included notably home range measurements, or straight-line distance travelled for animals. There were also a number of studies that focused on demography metrics (220 translocations) i.e. changes in the number of individuals, males/ females, of the translocated population overtime. Reproduction was the fourth most studied outcome metric (165 translocation studied reproduction in the following months or years). This included any study expressing findings on the number of young born since translocation. Comparatively, few studies focused on physiology (72), behaviour (83), genetics (68), and feeding (57). These are still important aspects to take into account especially when attempting to define if a project is a success or not. In the case of behaviour, social structure and cohesion, social roles and social learning may all be important to consider in building populations that are resilient and likely to persist in the long term [75]. Also, understanding the physiology and wellbeing of individuals either before or after release are also important factors to consider [76], and may be particularly useful in predicting long term survival rates for future interventions.

\section{Financial costs}

Financial costs were reported in only 23 translocations. Large differences in costs were reported. This was notably due to a choice of expenditure details expressed by authors. Some articles reported total project costs, 


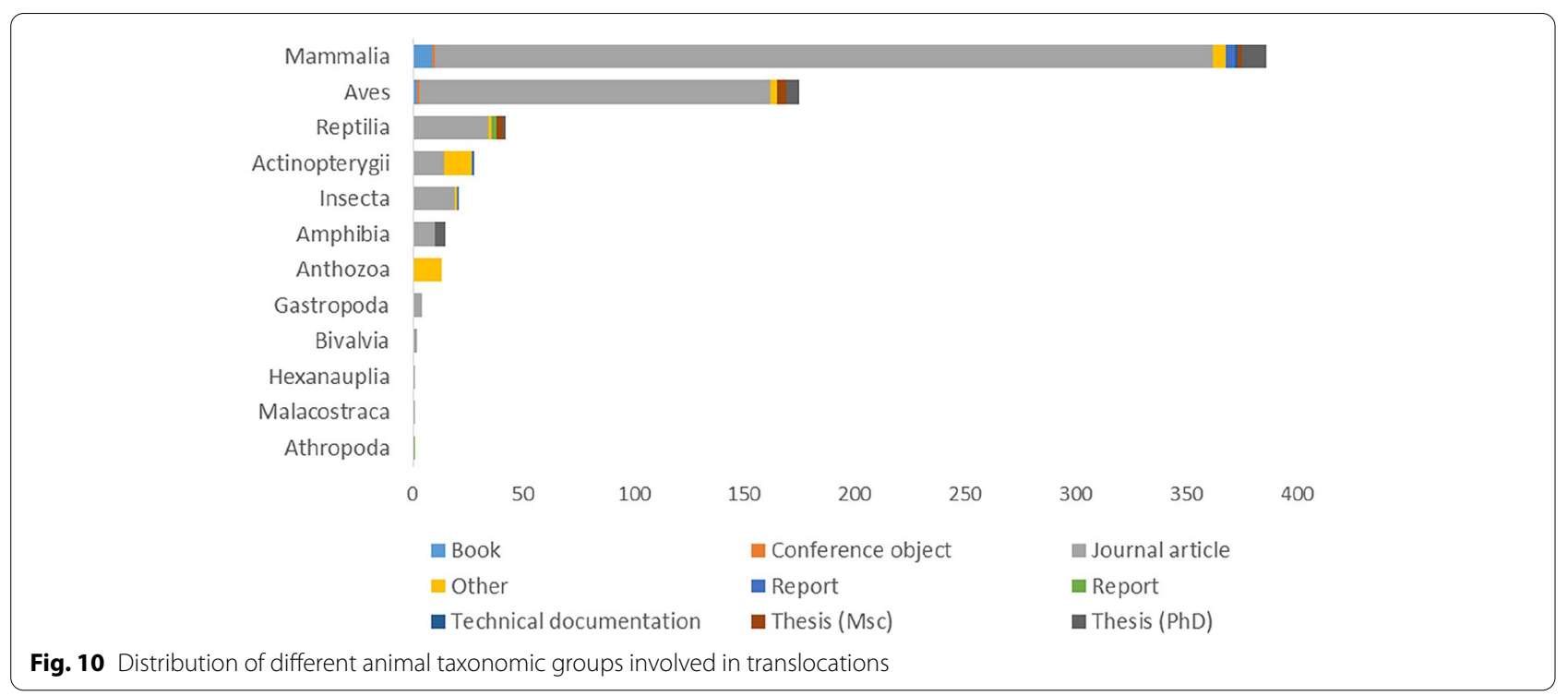

while others, for instance, only reported transfer modality costs excluding salaries or other expenditures commonly associated with translocation programmes. For example, Kenup et al. [77], reported total costs of $\$ 6300$ which included monitoring, captivity and release of Dasyprocta leporina. Whereas Bennett et al. [78] reported total expenditures of up to $\$ 185,000$ for a reintroduction project of Climacteris picumnus. Baker et al. 2012 supplementation efforts including 50 individuals of Dasyornis brachypterus cost upwards of AU\$200,000 [79], which included total expenditures from financing Ph.D. students to capture and release modalities. Muths et al. [80], an intervention including the transfer of eggs (Bufo boreas), equated to $\$ 700$ (excluding salaries).

\section{A guide for managers}

Finally, due to the complexity, and quantity of data available in this map, we realise that not all data was able to be summarised. Thus, we provide a 'guide' for managers to navigate through the evidence base of Additional file 7 (Fig. 15), in order to gather data that they may perceive necessary and access the references of the original studies utilised for any aspect of the map that is of interest. Among other information, this should allow users of the map to extract information on the factors of success. However, attention must be applied to the term "success", we have not attempted to code if a study was successful or not because from a biological point of view this depends on many factors. Hence, we have only coded the factors that affect success (e.g. number of individuals translocated, the quality of release habitat which is indirectly illustrated by the IUCN protection status, the distances involved, whether acclimatisation measures are used). The evidence base provides an overview of existing management interventions, summarised in association with such important factors that must be considered when engaging in translocations.

\section{Unclear cases}

Our mapping methods were conservative in nature, this meant that a total of 65 translocations (39 animals, 26 plants) were excluded from the descriptive statistics due to lack of sufficient confirming evidence specifically on protected area context. However, there was also a lack of confirming information to outright exclude such publications during the full text screening stage. Authors conclude that these instances probably should, in truth, have been included in the map description but did not want to risk potential 'error bias'. Indeed, the authors of the map team feel that these cases merited coding for the rest of the variables and inclusion into an additional file (cf. sheet 5 of Additional file 7). Of these 65 translocations: two were introductions of animals (one bird, one fish species); 5 were one-off reintroductions ( 2 species of Mammalia, 1 species each of Aves, Mollusca, and Magnoliopsida); 11 reintroductions followed by supplementing the same species (concerning animals: 3 mammals, 1 fish, 1 bird, 1 amphibian, 1 Bivalvia. Plants: 3 Magnoliopsida, and 1 Liliopsida). 36 interventions were coded as Unknown due to lack of confirming information on intervention type. 
Table 4 Illustrating the total sum of individuals (Animalia) translocated across all years (1969-2020) by taxonomic class

\begin{tabular}{|c|c|c|c|c|c|c|c|c|c|}
\hline \multirow{2}{*}{$\begin{array}{l}\text { Animal } \\
\text { taxonomic } \\
\text { class }\end{array}$} & \multicolumn{7}{|c|}{ Age class as stated by authors } & \multirow{2}{*}{$\begin{array}{l}\text { Total ind } \\
\text { translocated }\end{array}$} & \multirow{2}{*}{$\begin{array}{l}\text { Total number } \\
\text { of coded } \\
\text { translocation } \\
\text { operations }\end{array}$} \\
\hline & Adults only & $\begin{array}{l}\text { Juveniles } \\
\text { only }\end{array}$ & $\begin{array}{l}\text { Adult and } \\
\text { Juveniles }\end{array}$ & $\begin{array}{l}\text { Adult, } \\
\text { Juveniles, } \\
\text { and Larva }\end{array}$ & Instar only & Larva only & $\begin{array}{l}\text { Unknown } \\
\text { age class }\end{array}$ & & \\
\hline Mammalia & $\begin{array}{l}55,094 \\
(529 \pm 5129) \\
\mathbf{2 0}\end{array}$ & $\begin{array}{l}310(31 \pm 61) \\
\mathbf{3 8}\end{array}$ & $\begin{array}{l}6147 \\
(81 \pm 165) \\
\mathbf{5 1}\end{array}$ & - & - & - & $\begin{array}{l}10,159 \\
(64 \pm 127) \\
\mathbf{2 9}\end{array}$ & 71,710 & 383 \\
\hline Aves & $\begin{array}{l}910(43 \pm 35) \\
\mathbf{1 8}\end{array}$ & $\begin{array}{l}4637 \\
(122 \pm 160) \\
\mathbf{4 6}\end{array}$ & $\begin{array}{l}1327(60 \pm 39) \\
56\end{array}$ & - & - & - & $\begin{array}{l}6160 \\
(87 \pm 189) \\
\mathbf{2 9}\end{array}$ & 13,034 & 175 \\
\hline Reptilia & $\begin{array}{l}296(27 \pm 16) \\
\mathbf{2 3}\end{array}$ & $\begin{array}{l}149(75 \pm 100) \\
\mathbf{3 8}\end{array}$ & $\begin{array}{l}1081(77 \pm 82) \\
51\end{array}$ & - & - & - & $\begin{array}{l}4684 \\
(335 \pm 673) \\
65\end{array}$ & 6210 & 42 \\
\hline $\begin{array}{l}\text { Actinop- } \\
\text { terygii }\end{array}$ & - & $1955^{a}$ & $\begin{array}{l}6516 \\
(2172 \pm 1811) \\
69\end{array}$ & - & - & - & $\begin{array}{l}6420 \\
(279 \pm 550) \\
\mathbf{3 0}\end{array}$ & 14,891 & 28 \\
\hline Insecta & $\begin{array}{l}5995 \\
(545 \pm 983) \\
\mathbf{2 0}\end{array}$ & $\begin{array}{l}644(161 \pm 57) \\
36\end{array}$ & - & - & $1010^{\mathrm{a}}$ & $220^{a}$ & $\begin{array}{l}1350 \\
(337 \pm 261) \\
26\end{array}$ & 9219 & 21 \\
\hline Amphibia & $\begin{array}{l}6031 \\
(2010 \pm 3378) \\
\mathbf{2 1}\end{array}$ & $\begin{array}{l}12,424 \\
(3106 \pm 5264) \\
\mathbf{3 8}\end{array}$ & $1594^{\mathrm{a}}$ & $3783^{\mathrm{a}}$ & - & - & - & 23,832 & 15 \\
\hline Anthozoa & - & - & - & - & - & - & $\begin{array}{l}65(5 \pm 6) \\
\mathbf{2 2}\end{array}$ & 65 & 13 \\
\hline Gastropoda & - & - & $\begin{array}{l}765 \\
(383 \pm 388) \\
\mathbf{4 5}\end{array}$ & - & - & - & $\begin{array}{l}192 \\
(96 \pm 20) \\
\mathbf{3 1}\end{array}$ & 957 & 4 \\
\hline Bivalvia & - & - & - & - & - & - & $\begin{array}{l}200 \\
(100 \pm 71) \\
\mathbf{2 7}\end{array}$ & 200 & 2 \\
\hline Athropoda & - & - & - & - & - & - & $60^{a}$ & 60 & 1 \\
\hline Hexanauplia & - & - & - & - & - & - & - & Unknown & 1 \\
\hline Malacosraca & $62^{\mathrm{a}}$ & - & - & - & - & - & - & 62 & 1 \\
\hline $\begin{array}{l}\text { Total ind } \\
\text { translocated }\end{array}$ & 68,388 & 20,119 & 17,430 & 3783 & 1010 & 220 & 29,290 & 140,240 & 686 \\
\hline
\end{tabular}

In parentheses: average \pm standard deviation. Figures in bold represent the median number of individuals translocated.'-' no available data. “Unknown" signifies that for the given translocation events exact numbers of individuals are not known

a Denotes a single translocation event, thus no median, mean or standard deviation are calculated

\section{Comparison to other reviews}

Relating our current findings to others evidence syntheses may be useful for managers and policy makers. To our knowledge no other systematic map exists on wildlife translocations. However, map-like reviews (hereafter referred to as 'overviews') do exist providing some state of knowledge. But given the large differences in terms of methodology, topic scope, and volume of literature exposed in Table 8 , it was deemed difficult to make legitimate graphical comparisons. For instance, of the 4 overviews compared to our map, none included all biodiversity (terrestrial and marine animals, plants and fungi), or else their exclusion criteria was difficult to ascertain. Concerning three overviews of which only animals were the scope, mammals and birds were consistently the most translocated groups. Fischer and Lindenmayer [45], found that over
$50 \%$ of studies considered were performed with mammals and approximately $43 \%$ with birds. In an overview on key-stone species, $54 \%$ of publications focused solely on mammals [55]. Further, in a recent overview by Rescendre et al. [56], Diprotodontia was the highest represented mammal order, although in our map it was Artiodactyla (notably, but not exclusively, Bovidae, and Cervidae). Concerning supplementations, Fischer and Lindenmayer [45] showed that only birds and mammals were involved, although our map synthesises information from 8 different animal taxonomic classes, 3 plant classes and 1 fungi class in respect to supplementations. In terms of release strategies, birds were most commonly soft released $[51,56]$, our map also adheres to their findings: $67 / 175$ bird translocations used soft release measures. Although in our map, release measures for 95/175 were unknown. Despite the diversity of 


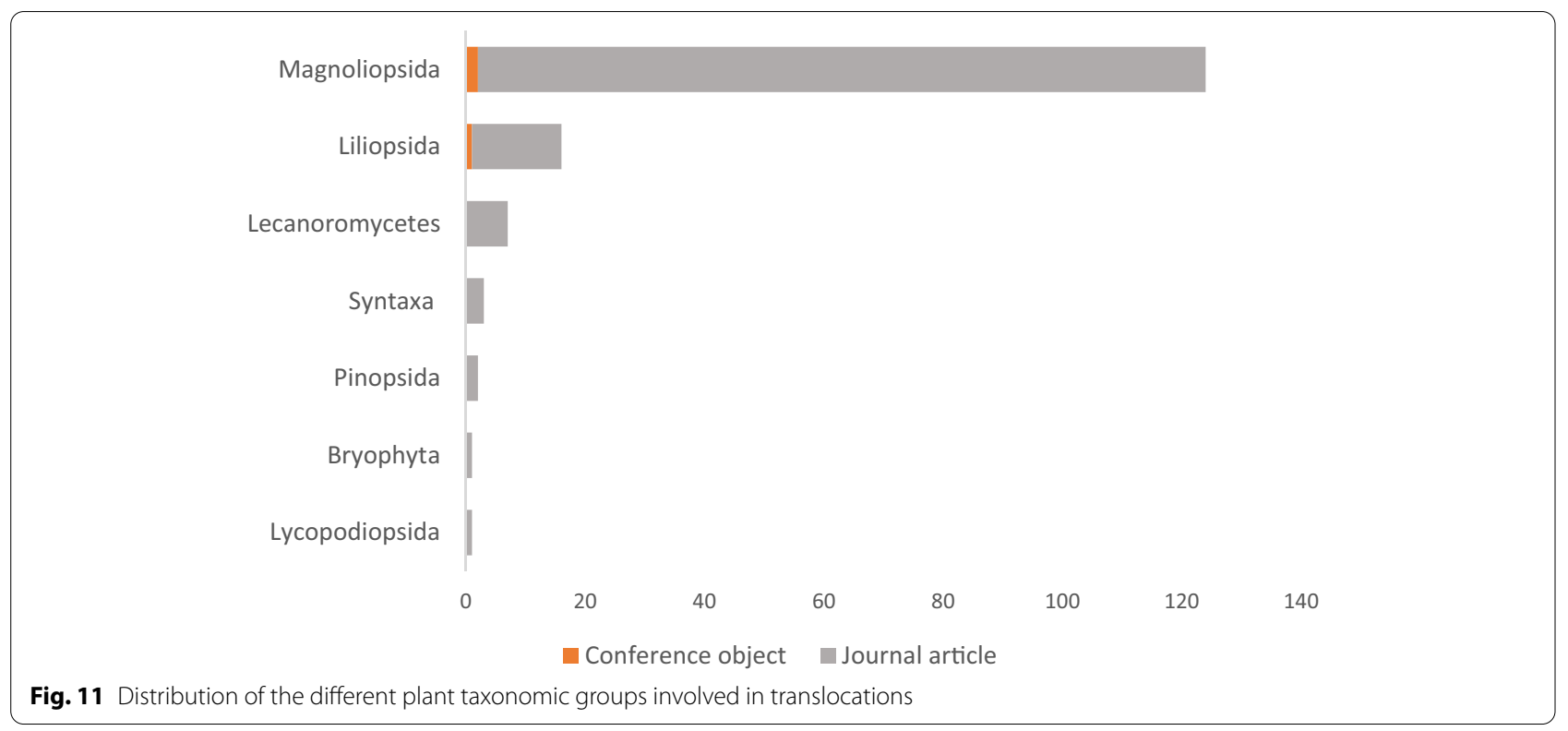

methods, we are able to demonstrate some consistency with previous overviews. However, the differences justify the need to have undertaken a systematic search of the existing literature in order to provide a clearer and more comprehensive state of knowledge.

\section{Limitations of the systematic map Search string}

The search strategy used to generate this systematic map was designed to capture a large breadth of relevant literature, not only on wildlife translocations but specifically in the context of protected areas. However, there does exist a certain diversity of terminology used on the subject of translocations (i.e., some terms may have been missed that could result in bias in our evidence map). For example, in general there were fewer studies evaluating plant translocations. In our search string, we did not use specific terms such as transplantation or transplant* which may have otherwise retrieved more studies on plant species. However, we did carefully scope our search string for intervention terms by including several synonyms (e.g. "assisted colonization", "assisted migration", etc.). In addition, our comprehensiveness was very high (see "Testing the comprehensiveness of the search results" section).

\section{Language}

Translocation is often carried out by managers of natural areas or communities. It is therefore possible that the reintroduction experiences are largely recounted in grey literature because these actors are less used to producing academic literature. Also, this type of document is often published in the language of each country rather than in English like scientific articles. Our search strategy included several sources of grey literature (4 web-based search engines, 5 specialist websites and an explicit call for grey literature). However, the fact that only English terms were used for our searches and that the call for literature was broadcast in French may have limited the recovery of grey literature written in a native languages other than English and French. In addition, 28 articles retrieved by our English search terms were not written in English and were excluded during the full-text screening stage in accordance with our screening criteria (Additional file 9): Spanish, 8; German, 7; Chinese 5; other languages, 8 . However, it is unclear how many of these articles would have met all the inclusion criteria. Finally, our systematic map is likely to have underestimated the reality of the translocation cases regarding these language limitations due to a lack of time and skills.

\section{Consistency}

As explained in "Deviation from the protocol" section, we were not able to perform our Kappa test on $10 \%$ of retained eligible full-texts. Due to time constraints, we based our kappa test on $5 \%$ of the eligible corpus. We are aware that the assessment of our consistency at the full-text screening stage is therefore necessarily lower than expected. Nevertheless, $5 \%$ of all the full-texts to be screened (1182) represented 59 articles; this is already a large enough sample to meet different types of publications and to highlight possible disagreements. Moreover, the result of this full-text Kappa test 


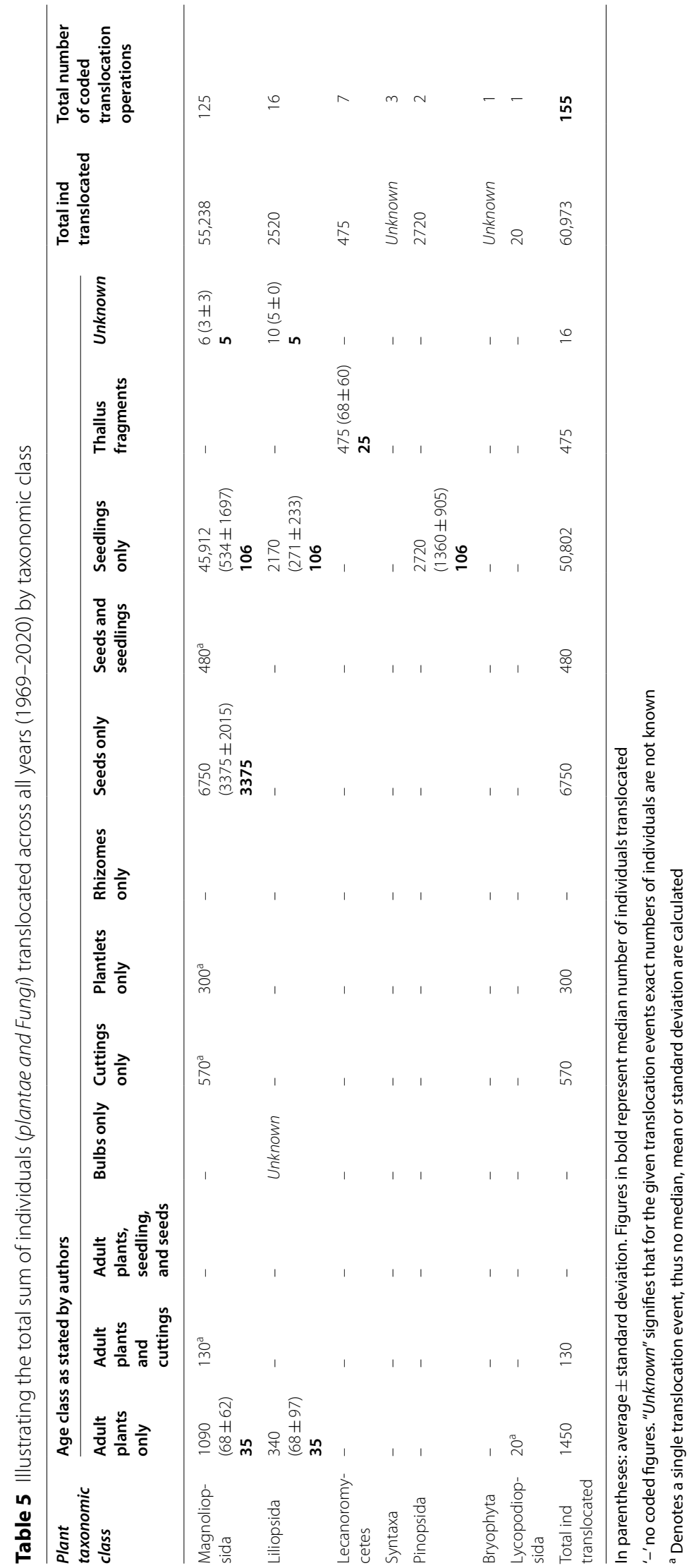


Table 6 Number of translocation events (whether reintroduction, supplementation or introduction or a combination) for animals, by taxonomic class and age at release

\begin{tabular}{|c|c|c|c|c|c|c|}
\hline \multirow{2}{*}{ Taxonomic class $\mathrm{X}$ age } & \multicolumn{6}{|c|}{ Intervention type. } \\
\hline & Intro+suppl & Introduction & Reintro+suppl & Reintroduction & Supplementation & Unknown \\
\hline Actinopterygii & & & 4 & 2 & 10 & 12 \\
\hline Adults + Juveniles & & & 3 & & & \\
\hline Juveniles only & & & 1 & & & \\
\hline Unknown & & & & 2 & 10 & 12 \\
\hline Amphibia & 1 & & 2 & 3 & 2 & 7 \\
\hline Adults only & & & & 1 & 1 & 1 \\
\hline Adults + Juveniles & & & & & & 1 \\
\hline Adults + Juveniles + Larva & & & 1 & & & \\
\hline Eggs only & & & & & & 1 \\
\hline Juveniles only & 1 & & 1 & 1 & 1 & \\
\hline Unknown & & & & & & 5 \\
\hline Anthozoa & & & & & 13 & \\
\hline Unknown & & & & & 13 & \\
\hline Athropoda & & & & & & 1 \\
\hline Unknown & & & & & & 1 \\
\hline Aves & 2 & 2 & 54 & 43 & 40 & 34 \\
\hline Adults only & & 2 & 6 & 8 & 3 & 2 \\
\hline Adults + Juveniles & & & 11 & 2 & 6 & 3 \\
\hline Juveniles only & 1 & & 12 & 6 & 13 & 6 \\
\hline Unknown & 1 & & 25 & 27 & 18 & 23 \\
\hline Bivalvia & & & & & & 2 \\
\hline Unknown & & & & & & 2 \\
\hline Gastropoda & & & & 1 & 3 & \\
\hline Adults + Juvenile & & & & & 2 & \\
\hline Unknown & & & & 1 & 1 & \\
\hline Hexanauplia & & & & & & 1 \\
\hline Unknown & & & & & & 1 \\
\hline Insecta & 1 & 2 & 5 & 4 & 4 & 5 \\
\hline Adults only & 1 & 2 & 2 & 1 & 3 & 2 \\
\hline Instar & & & & 1 & & \\
\hline Juveniles only & & & 1 & 1 & 1 & 1 \\
\hline Larva only & & & 1 & & & \\
\hline Unknown & & & 1 & 1 & & 2 \\
\hline Malacosraca & & & & 1 & & \\
\hline Adults only & & & & 1 & & \\
\hline Mammalia & 2 & 2 & 101 & 94 & 75 & 109 \\
\hline Adults only & & 1 & 23 & 19 & 32 & 29 \\
\hline Adults + Juveniles & & & 25 & 13 & 17 & 22 \\
\hline Juveniles only & & & 1 & 3 & 5 & 1 \\
\hline Unknown & 2 & 1 & 52 & 59 & 21 & 57 \\
\hline Reptilia & & & 10 & 10 & 11 & 11 \\
\hline Adults only & & & 5 & 2 & 3 & 1 \\
\hline Adults + Juveniles & & & 4 & 4 & & 6 \\
\hline Juveniles only & & & & & 2 & 1 \\
\hline Unknown & & & 1 & 4 & 6 & 3 \\
\hline
\end{tabular}


Table 7 Number of translocation events (whether reintroduction, supplementation or introduction or a combination) for plants and fungi, by taxonomic class and age at release

\begin{tabular}{|c|c|c|c|c|c|c|}
\hline & \multirow{2}{*}{ Taxonomic class $X$ age } & \multicolumn{5}{|c|}{ Intervention type } \\
\hline & & Introduction & Reintro+Suppl. & Reintroduction & Supplementation & Unknown \\
\hline \multirow[t]{3}{*}{ Fungi } & & & & 4 & 3 & \\
\hline & Lecanoromycetes & & & 4 & 3 & \\
\hline & Thallus fragments & & & 4 & 3 & \\
\hline \multirow[t]{25}{*}{ Plantae } & & 4 & 10 & 11 & 41 & 82 \\
\hline & Bryophyta & & & 1 & & \\
\hline & Adult plant & & & 1 & & \\
\hline & Liliopsida & & 3 & 1 & 9 & 3 \\
\hline & Adult plants only & & & & 4 & 1 \\
\hline & Bulbs only & & 1 & & & \\
\hline & Seedlings only & & 2 & 1 & 3 & 2 \\
\hline & Unknown & & & & 2 & \\
\hline & Lycopodiopsida & & & 1 & & \\
\hline & Adult plants & & & 1 & & \\
\hline & Magnoliopsida & 4 & 7 & 8 & 31 & 75 \\
\hline & Adult plants only & & & 5 & 5 & 6 \\
\hline & Adult plants + Cutting & & & 1 & & \\
\hline & Adult Plants + Seedling + Seed & & 1 & & & \\
\hline & Cuttings only & & & & 2 & 1 \\
\hline & Plantlets only & & 3 & & & 1 \\
\hline & Rhizome only & & 1 & & & \\
\hline & Seeds only & 1 & & & & 1 \\
\hline & Seeds + Seedlings & & & & 1 & \\
\hline & Seedlings only & 1 & 2 & 1 & 23 & 63 \\
\hline & Unknown & 2 & & 1 & & 3 \\
\hline & Pinopsida & & & & 1 & 1 \\
\hline & Seedlings only & & & & 1 & 1 \\
\hline & Syntaxa & & & & & 3 \\
\hline & Seeds only & & & & & 3 \\
\hline
\end{tabular}

"Syntaxa" refers to where more than one class were translocated at the same time

was excellent (0.93) with disagreements only on two full-texts. This confirmed that carrying out the full-text Kappa test on 5\% was not detrimental to the rigour of the systematic map.

Regarding the coding step (extraction of the metadata), the systematic map protocol provided, as a first option, a real double coding for each article. In case of time constraints, it provided as a second option, that an a posteriori cross-check could be carried out with discussion between the coders on potential disagreements. Concerning the current project, due to the lack of means, we had to choose this alternative. We think that our approach did not affect coding consistency because (1) the coders followed the same rules, (2) a test of consistency was carried out before starting, with discussions on the potential disagreements, (3) all the reviewers were in contact throughout the coding process, and (4) an a posteriori check was undertaken at the end of the coding step (see "Data coding strategy" section for more details).

\section{Conclusions}

This systematic map provides an up-to-date global catalogue of the available evidence on wildlife translocations to, from, or within protected areas. From the translocation synthesis, we identified a total of 498 publications equating to 841 translocations. Documented translocations were a result of various motivations but mainly driven by an aim to improve the conservation status of the focal species (it should also be noted that a large number of translocations did not mention any information on motivation). Translocation operations spanned a range of north and southern hemisphere regions (69 countries worldwide). Most studies aimed 


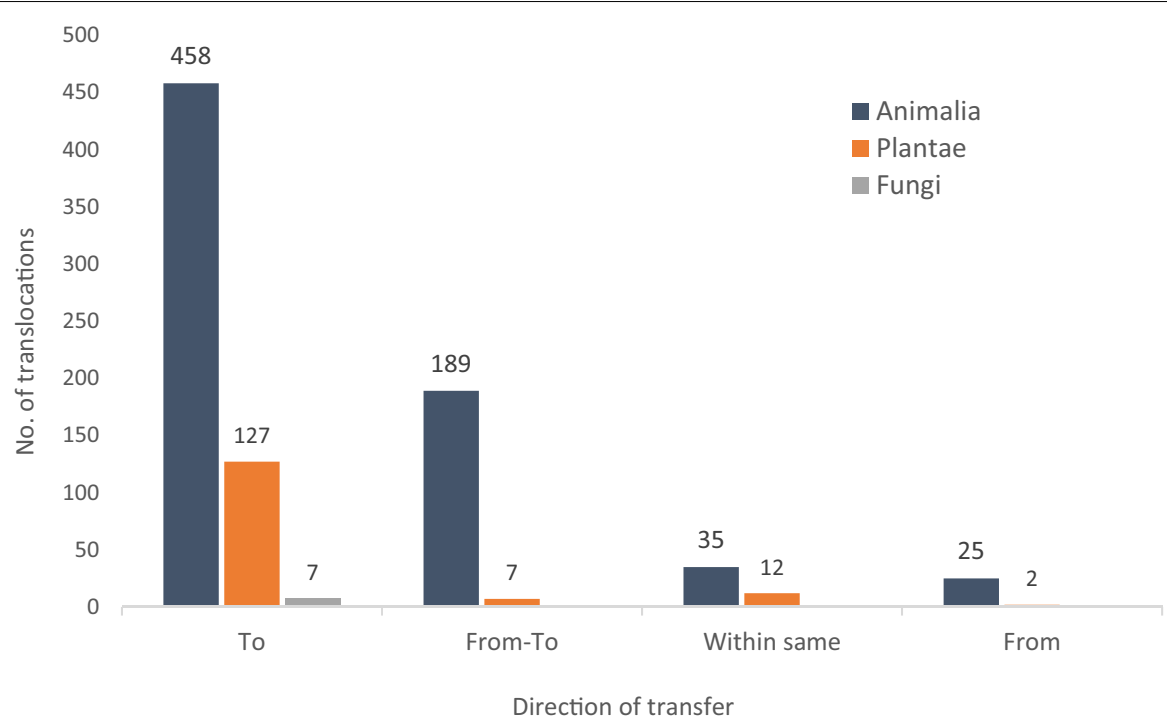

Figure. 12. The number of translocations and their "direction" of transfer i.e. protected area context by taxonomic kingdom. "To": transfer from a non-protected area (PA) to a PA; "From-To": transfer from a PA to another; "Within same": transfer occurring within the same PA perimeter; "From": transfer from a PA to outside of PA. N.B., only known direction of movement is presented in the current figure

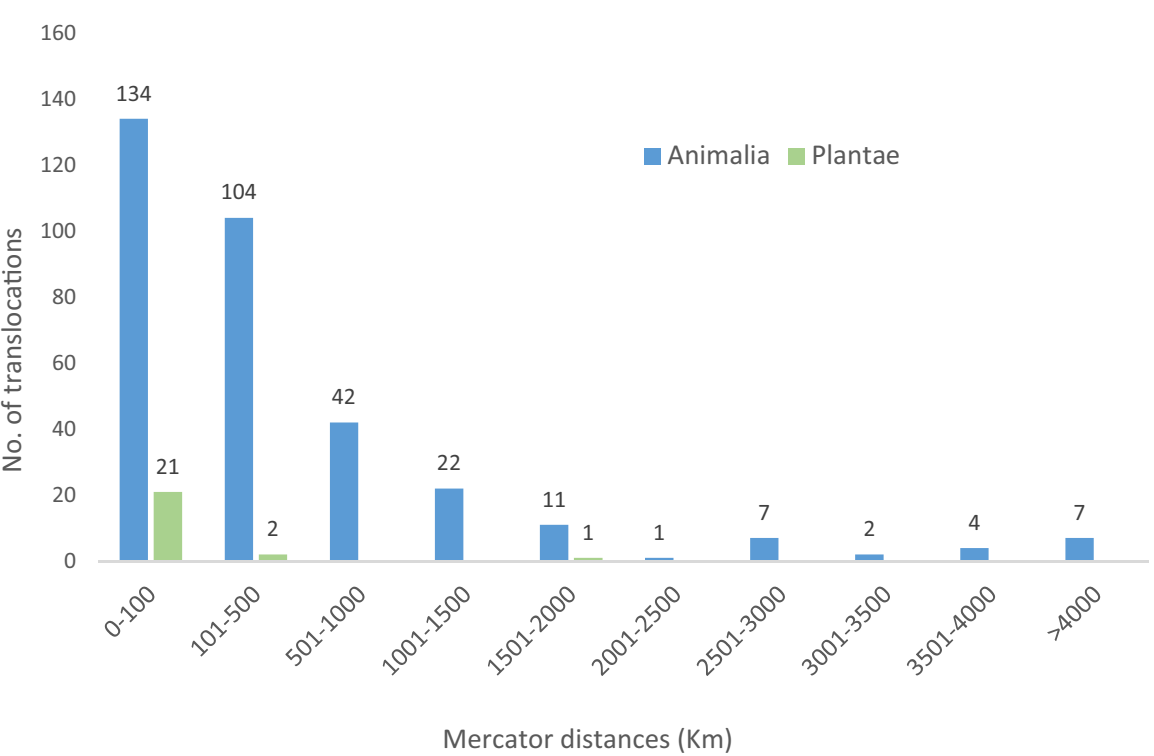

Fig. 13 Number of translocations by distance (in kilometres). N.B., This is only based on the number of translocations (358) where sufficient information was available in the publications to collate geographic coordinates either directly by authors or with detailed enough information given on capture and release sites to be able to retrieve coordinates manually

at assessing the survival, space use, demography, and reproduction of translocated species. To a lesser extent, the impacts on feeding habitats, behaviour, genetics, and physiology were also studied. The most translocated animal groups included mammals, birds, and reptiles, while the most translocated plant groups were Magnoliopsida and Liliopsida. The majority of species are translocated to protected areas from non-protected sites.

\section{Implications for policy/management}

Given the map focused on translocations related to protected areas, the results are addressed primarily to their managers. The map database provides an estimate of the 


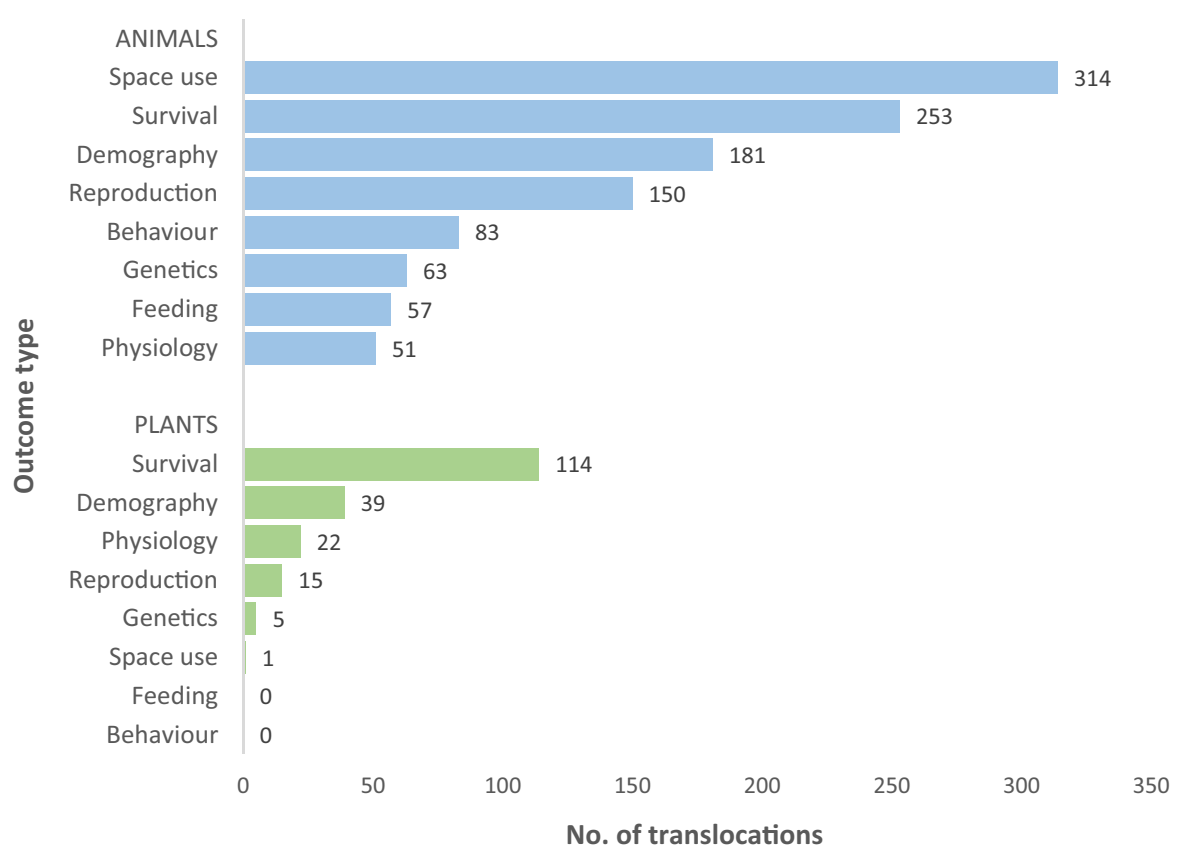

Fig. 14 Number of translocations by type of outcome studied

extent of conservation translocations carried out worldwide, in which protected areas are involved, concerning all biodiversity (fauna, flora, fungi). In this respect, it should enable protected area managers to better perceive their role, in the global network of protected areas, both as suppliers or recipients of translocated organisms. Also, it could aid managers and practitioners in making their own choices by comparing previous experiences, regarding both the species concerned and the precise translocation modalities (number of individuals, etc.) (cf. Fig. 15 for a 'walkthrough' on how to navigate the database). Thus, at a time where reserve managers may be increasingly questioning whether to take such 'risk-based' actions, a detailed view of such interventions is clearly needed. As a consequence, the systematic map database provides valuable information to support decision making for future translocations. It may also be of interest to institutions and NGOs alike (i.e. Ministries, IUCN, etc.). If certain questions emerge from managers and decision makers, the map could also be used to develop one or more systematic reviews (for example to quantify the success factors involved in the survival of translocated individuals), which would further help guide decisions on future translocations.

\section{Implications for research}

The results of the current systematic map clearly identify that the evidence of translocations is skewed towards assessing survival (i.e. proportion of individuals alive or level of mortality since translocation), demography (i.e. population growth overtime), and space use (i.e. the dispersal and home range distances). However, the impacts on the behavior, genetics, and physiology of translocated individuals will undoubtedly contribute to the longterm success of such interventions. Thus, we encourage researchers to study translocations using these outcomes to diversify the results. As a second point, this map identifies a number of groups that were associated with a few number of publications, such as Anthozoa, Gastropoda, Bivalvia, Athropoda, Hexanauplia, Malacosraca. This could be a lack of publications on existing translocations or a real absence of translocations for these species in question. It might be interesting to carry out further work to check whether certain translocations exist of which this map would therefore be unaware because they have not been published (which is in line with the limitations mentioned above on language restrictions, for example).

Lastly, concerning intervention type, 264/841 translocations were coded as Unknown. Indeed, the authors were unable to code with sufficient confidence whether the concerned translocations consisted of a true reintroduction, supplementation, or introduction. This was mainly due to either a lack of consistency or miss use of translocation vocabulary, or missing confirming information on in situ resident populations, or historical species' distributions. We therefore underline the importance of using correct vocabulary and encourage future research to systematically publish details in the "Materials and 


\section{Flow diagram for managers navigating the evidence base - Additional File 7}

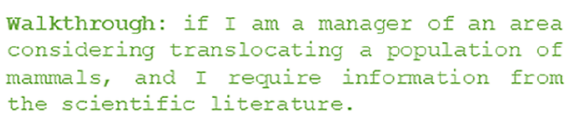

Download Additional File 7. Open sheet " 5 . Translocation synthesis (498)"

N.B., 498 is the total number of publications retained for the Translocation synthesis.

841 is the number of unique translocation operations coded from the 498 publications
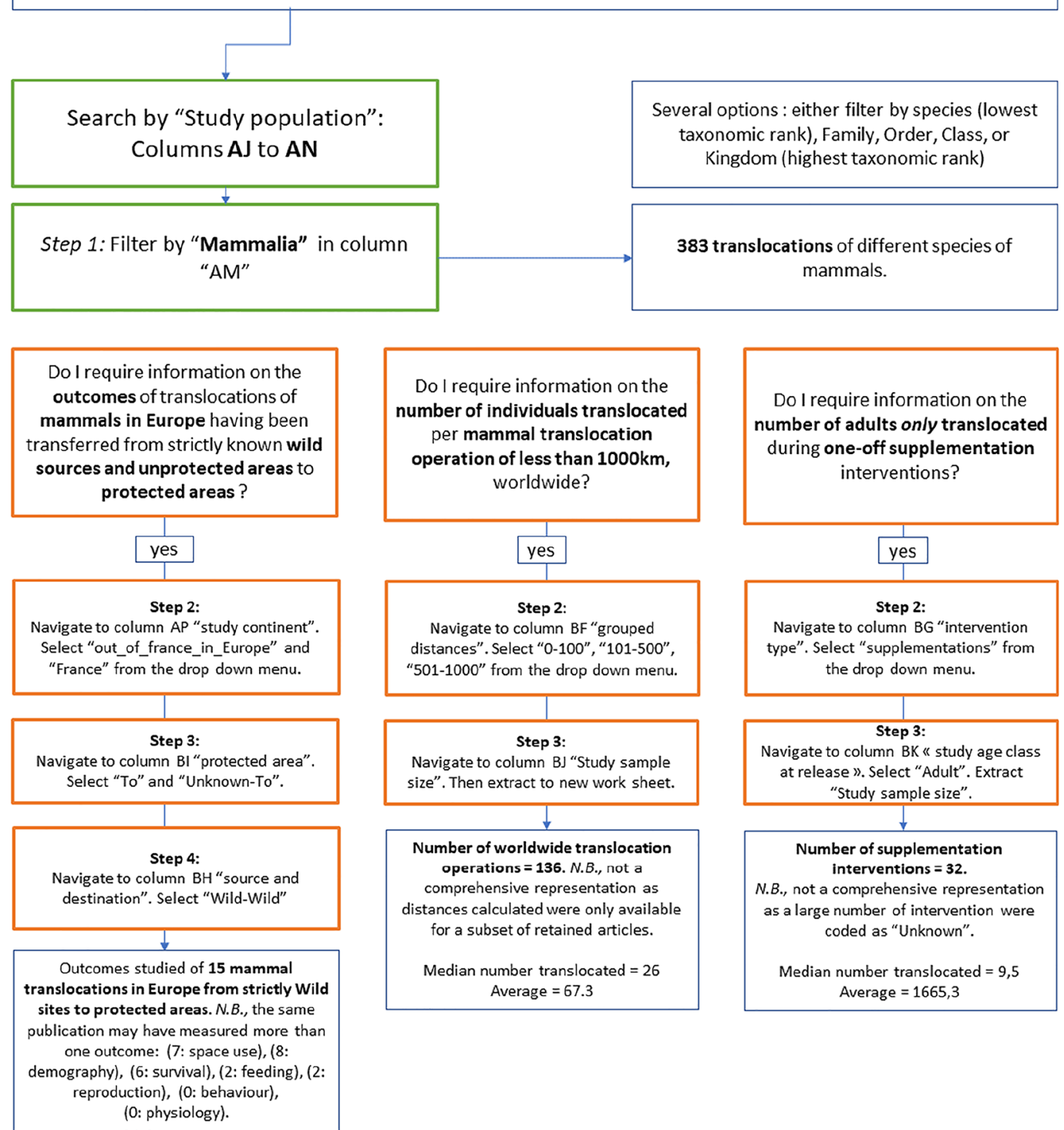

Fig. 15 illustrates how to navigate through the evidence base. Three walkthroughs are provided based on searching for information on mammal translocations. N.B., these example questions are adapted from real operational inquiries addressed to the review team during workshops 


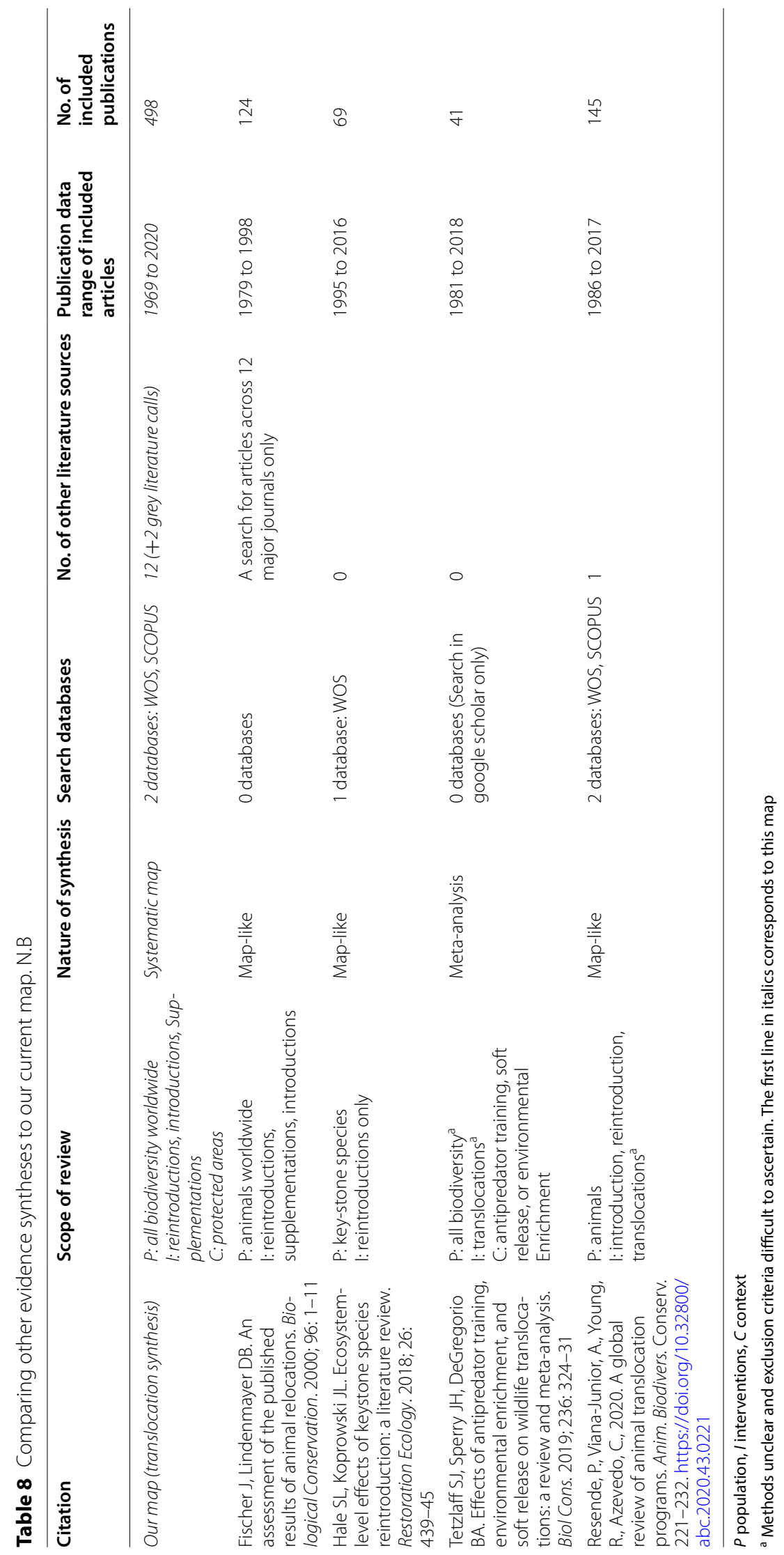


methods" section of articles the exact context of a translocation intervention so that future map and review projects can incorporate as much metadata as possible.

\section{Supplementary Information}

The online version contains supplementary material available at https://doi. org/10.1186/s13750-021-00236-w.

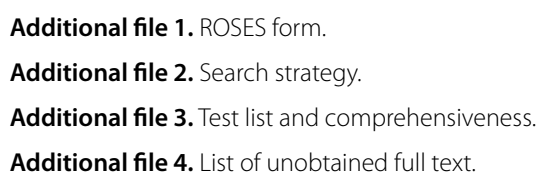

Additional file 6. List of accepted articles (all, unclear contexts, reviews/ metapopulation management, translocation synthesis).

Additional file 7. List of studies (all, unclear contexts, link data, translocation synthesis).

Additional file 8. Calculating distances in $\mathrm{R}$.

Additional file 9. List of rejected articles on language.

\section{Acknowledgements}

The authors would like to thank Dr. Hugo Mell for his contribution to full-text screening and coding; and Dr. Benoît Pisanu of the Natural heritage service (UMS Patrimoine Natural OFB-CENRS-MNHN), notably for his expertise and knowledge on managing and analysing geographic data.

\section{Authors' contributions}

This systematic map is based on a protocol, Langridge et al. [60], written by $J L, R S$, and YR. JL and RS undertook searches, screening, and coding of articles. HM coded articles. JL and RS wrote the manuscript. All authors read and approved the final manuscript.

\section{Authors' information}

$J, R S, H M, Y R$ are scientists.

\section{Funding}

This work was undertaken within the framework of the LIFE program entitled "Natur'Adapt". The project is co-financed by the LIFE programme (European commission), The French Ministry of Ecology and the French Office of Biodiversity.

\section{Availability of data and materials}

All data, generated or analysed during this systematic map are included in this published article and its Additional files.

\section{Declarations}

Ethics approval and consent to participate

Not applicable.

\section{Consent for publication}

Not applicable.

\section{Competing interests}

The authors declare having no competing interests.

Received: 15 March 2021 Accepted: 27 August 2021

Published online: 30 October 2021

\section{References}

1. Vitousek PM, Mooney HA, Lubchenco J, Melillo JM. Human domination of earth's ecosystems. Science. 1997;277:494-9.

2. Murphy SE, Greenaway F, Hill DA. Patterns of habitat use by female brown long-eared bats presage negative impacts of woodland conservation management. J Zool. 2012;288:177-83.

3. Ceballos G, Ehrlich PR, Barnosky AD, García A, Pringle RM, Palmer TM. Accelerated modern human-induced species losses: entering the sixth mass extinction. Sci Adv. 2015;1:e1400253.

4. Newbold T, Hudson LN, Hill SLL, Contu S, Lysenko I, Senior RA, et al. Global effects of land use on local terrestrial biodiversity. Nature. 2015;520:45-50.

5. Nowakowski AJ, Thompson ME, Donnelly MA, Todd BD. Amphibian sensitivity to habitat modification is associated with population trends and species traits. Glob Ecol Biogeogr. 2017;26:700-12.

6. IUCN. The IUCN global species programme. IUCN. 2015. https://www. iucn.org/theme/species/about/iucn-global-species-programme. Accessed 12 May 2021.

7. Griffith B, Scott J, Carpenter J, Reed C. Translocation as a species conservation tool: status and strategy. Science. 1989;245:477-80.

8. Chapin FS, Zavaleta ES, Eviner VT, Naylor RL, Vitousek PM, Reynolds HL, et al. Consequences of changing biodiversity. Nature. 2000;405:234-42.

9. Rockström J, Steffen W, Noone K, Persson Å, Chapin FS, Lambin EF, et al. A safe operating space for humanity. Nature. 2009;461:472-5.

10. Zari MP. Ecosystem services analysis in response to biodiversity loss caused by the built environment. SAPIENS Surveys and Perspectives Integrating Environment and Society. Institut Veolia Environnement; 2014. http://journals.openedition.org/sapiens/1684. Accessed 15 Feb 2021.

11. Steffen W, Richardson K, Rockström J, Cornell SE, Fetzer I, Bennett EM, et al. Planetary boundaries: guiding human development on a changing planet. Science. 2015;347. https://science.sciencemag.org/content/ 347/6223/1259855. Accessed 12 May 2021.

12. Dudley N, Shadie P, Stolton S. Guidelines for applying protected area management categories including IUCN WCPA best practice guidance on recognising protected areas and assigning management categories and governance types. IUCN; 2013. https://portals.iucn.org/library/ node/30018. Accessed 18 May 2021.

13. Cantú-Salazar L, Gaston K. Very large protected areas and their contribution to terrestrial biological conservation. Bioscience. 2010;60:808-18.

14. Boucher TM, Spalding M, Revenga $C$. Role and trends of protected areas in conservation. In: Levin SA, editor. Encyclopedia of biodiversity, 2nd edition. Waltham: Academic Press; 2013. p. 485-503. https://www.sciencedir ect.com/science/article/pii/B9780123847195003488. Accessed 12 May 2021.

15. IUCN. Guidelines for reintroductions and other conservation translocations. IUCN; 2013. https://portals.iucn.org/library/node/10386. Accessed 12 May 2021.

16. Turner IM, Corlett RT. The conservation value of small, isolated fragments of lowland tropical rain forest. Trends Ecol Evol. 1996;11:330-3.

17. Schwartz MW, van Mantgem PJ. The value of small preserves in chronically fragmented landscapes. In: Schwartz MW, editor. Conservation in highly fragmented landscapes. Boston: Springer; 1997. p. 379-94. https:// doi.org/10.1007/978-1-4757-0656-7_16.

18. IUCN. Guidelines for reintroductions and other conservation translocations. IUCN; 2013. https://www.iucn.org/content/guidelines-reintroduc tions-and-other-conservation-translocations. Accessed 31 Oct 2019.

19. Seddon PJ, Griffiths CJ, Soorae PS, Armstrong DP. Reversing defaunation: restoring species in a changing world. Science. 2014;345:406-12.

20. Cheyne S. Wildlife reintroduction: considerations of habitat quality at the release site. BMC Ecol. 2006;6:5.

21. Moorhouse TP, Gelling M, Macdonald DW. Effects of habitat quality upon reintroduction success in water voles: evidence from a replicated experiment. Biol Conserv. 2009;142:53-60.

22. Godefroid S, Piazza C, Rossi G, Buord S, Stevens A-D, Aguraiuja R, et al. How successful are plant species reintroductions? Biol Conserv. 2011;144:672-82.

23. Stadtmann S, Seddon PJ. Release site selection: reintroductions and the habitat concept. Oryx. 2020;54:687-95. 
24. Peters RL, Darling JDS. The greenhouse effect and nature reserves global warming would diminish biological diversity by causing extinctions among reserve species. Bioscience. 1985;35:707-17.

25. Seddon PJ. From reintroduction to assisted colonization: moving along the conservation translocation spectrum. Restor Ecol. 2010;18:796-802.

26. Kostyack J, Lawler JJ, Goble DD, Olden JD, Scott JM. Beyond reserves and corridors: policy solutions to facilitate the movement of plants and animals in a changing climate. Bioscience. 2011;61:713-9.

27. Lunt ID, Byrne M, Hellmann JJ, Mitchell NJ, Garnett ST, Hayward MW, et al. Using assisted colonisation to conserve biodiversity and restore ecosystem function under climate change. Biol Conserv. 2013;157:172-7.

28. Watson J, Dudley N, Segan D, Hockings M. The performance and potential of protected areas. Nature. 2014;515:67-73.

29. Heller NE, Zavaleta ES. Biodiversity management in the face of climate change: a review of 22 years of recommendations. Biol Conserv. 2009;142:14-32.

30. Prober SM, Doerr VAJ, Broadhurst LM, Williams KJ, Dickson F. Shifting the conservation paradigm: a synthesis of options for renovating nature under climate change. Ecol Monogr. 2019;89:e01333.

31. Sandom CJ, Dempsey B, Bullock D, Ely A, Jepson P, Jimenez-Wisler S, et al. Rewilding in the English uplands: policy and practice. J Appl Ecol. 2019;56:266-73.

32. Macias-Fauria M, Jepson P, Zimov N, Malhi Y. Pleistocene Arctic megafaunal ecological engineering as a natural climate solution? Philos Trans R Soc B Biol Sci. 2020;375:20190122.

33. Seddon PJ, Armstrong DP, Maloney RF. Developing the science of reintroduction biology. Conserv Biol. 2007;21:303-12.

34. Seddon P, Armstrong D. 2. Reintroduction and other conservation translocations: history and future developments. In: Reintroduction of fish and wildlife populations. Oakland: University of California Press; 2019. p. 7-28.

35. Abeli T, Cauzzi P, Rossi G, Pistoja F, Mucciarelli M. A gleam of hope for the critically endangered Isoëtes malinverniana: use of small-scale translocations to guide conservation planning. Aquat Conserv Mar Freshw Ecosyst. 2018;28:501-5.

36. Jolly CJ, Kelly E, Gillespie GR, Phillips B, Webb JK. Out of the frying pan: reintroduction of toad-smart northern quolls to southern Kakadu National Park. Austral Ecol. 2018;43:139-49.

37. Briers-Louw WD, Verschueren S, Leslie AJ. Big cats return to Majete wildlife reserve, Malawi: evaluating reintroduction success. Afr J Wildl Res. 2019:49:34-50.

38. Hitchcock A, Williams J, Cowell C. Lessons learned as Erica turgida is returned. J Nat Conserv. 2020;56:125858.

39. Moehrenschlager A, Macdonald DW. Movement and survival parameters of translocated and resident swift foxes Vulpes velox. Anim Conserv Forum. 2003;6:199-206.

40. Clements D. Translocation of rare plant species to restore Garry oak ecosystems in western Canada: challenges and opportunities. Botany 2013;91:283-91.

41. Jackson CL, Schuster R, Arcese P. Release date influences first-year site fidelity and survival in captive-bred Vancouver Island marmots. Ecosphere. 2016;7:e01314.

42. Steenweg R, Hebblewhite M, Gummer D, Low B, Hunt B. Assessing potential habitat and carrying capacity for reintroduction of plains bison (Bison bison bison) in Banff National Park. PLoS ONE. 2016;11:e0150065.

43. Sarrazin F, Barbault R. Reintroduction: challenges and lessons for basic ecology. Trends Ecol Evol. 1996;11:474-8.

44. McCoy ED, Osman N, Hauch B, Emerick A, Mushinsky HR. Increasing the chance of successful translocation of a threatened lizard. Anim Conserv. 2014;17:56-64.

45. Fischer J, Lindenmayer DB. An assessment of the published results of animal relocations. Biol Conserv. 2000;96:1-11.

46. Azar JF, Rautureau P, Lawrence M, Calabuig G, Hingrat Y. Survival of reintroduced Asian houbara in United Arab Emirates' reserves. J Wildl Manag. 2016;80:1031-9.

47. Brichieri-Colombi TA, Moehrenschlager A. Alignment of threat, effort, and perceived success in North American conservation translocations. Conserv Biol. 2016;30:1159-72.

48. Morris SD, Brook BW, Moseby KE, Johnson CN. Factors affecting success of conservation translocations of terrestrial vertebrates: a global systematic review. Glob Ecol Conserv. 2021;28:e01630.
49. Heiken KH, Brusch GA, Gartland S, Escallón C, Moore IT, Taylor EN. Effects of long distance translocation on corticosterone and testosterone levels in male rattlesnakes. Gen Comp Endocrinol. 2016;237:27-33.

50. de Milliano J, Stefano JD, Courtney P, Temple-Smith P, Coulson G. Softrelease versus hard-release for reintroduction of an endangered species: an experimental comparison using eastern barred bandicoots (Perameles gunnii). Wildlife. 2016;43:1-12.

51. Tetzlaff S, Sperry J, Degregorio B. Effects of antipredator training, environmental enrichment, and soft release on wildlife translocations: a review and meta-analysis. Biol Conserv. 2019;236:324-31.

52. Corlett RT. Restoration, reintroduction, and rewilding in a changing world. Trends Ecol Evol. 2016;31:453-62.

53. Mukesh, Sharma LK, Charoo SA, Sathyakumar S. Conflict bear translocation: investigating population genetics and fate of bear translocation in Dachigam National Park, Jammu and Kashmir, India. PLOS ONE. 2015;10:e0132005.

54. Harvey D, Lentini A, Cedar K, Weatherhead P. Moving massasaugas: insight into rattlesnake relocation using Sistrurus C. catenatus. Herpetol Conserv Biol. 2014;9:67-75.

55. Hale SL, Koprowski JL. Ecosystem-level effects of keystone species reintroduction: a literature review. Restor Ecol. 2018;26:439-45.

56. Resende P, Viana-Junior A, Young R, Azevedo C. A global review of animal translocation programs. Anim Biodivers Conserv. 2020;43:221-32.

57. McLachlan JS, Hellmann JJ, Schwartz MW. A framework for debate of assisted migration in an era of climate change. Conserv Biol. 2007:21:297-302.

58. Weeks AR, Sgro CM, Young AG, Frankham R, Mitchell NJ, Miller KA, et al. Assessing the benefits and risks of translocations in changing environments: a genetic perspective. Evol Appl. 2011;4:709-25.

59. Letty J, et al. Improving translocation success: an experimental study of anti-stress treatment and release method for wild rabbits. Anim Conserv Forum. 2000;3:211-9.

60. Langridge J, Sordello R, Reyjol Y. Outcomes of wildlife translocations in protected areas: what is the type and extent of existing evidence? A systematic map protocol. Environ Evid. 2020;9:16. https://doi.org/10.1186/ s13750-020-00199-4.

61. Guidelines for authors - environmental evidence. https://environmen talevidence.org/information-for-authors/. Accessed 22 Feb 2021.

62. Haddaway NR, Collins AM, Coughlin D, Kirk S. The role of google scholar in evidence reviews and its applicability to grey literature searching. PLoS ONE. 2015;10:e0138237. https://doi.org/10.1371/journal.pone.0138237.

63. James KL, Randall NP, Haddaway NR. A methodology for systematic mapping in environmental sciences. Environ Evid. 2016;5:7.

64. Fernandez FAS, Rheingantz ML, Genes L, Kenup CF, Galliez M, Cezimbra T, et al. Rewilding the Atlantic Forest: restoring the fauna and ecological interactions of a protected area. Perspect Ecol Conserv. 2017;15:308-14.

65. Bowler DE, Bjorkman AD, Dornelas M, Myers-Smith $I H$, Navarro LM, Niamir A, et al. Mapping human pressures on biodiversity across the planet uncovers anthropogenic threat complexes. People Nat. 2020;2:380-94.

66. Zimmer H, Auld T, Cuneo P, Offord C, Commander L. Conservation translocation - an increasingly viable option for managing threatened plant species. Aust J Bot. 2019;67:501-9.

67. Kottek M, Grieser J, Beck C, Rudolf B, Rubel F. World Map of the KöppenGeiger climate classification updated. Meteorol Z. 2006;15:259-63.

68. Beck HE, Zimmermann NE, McVicar TR, Vergopolan N, Berg A, Wood EF. Present and future Köppen-Geiger climate classification maps at 1-km resolution. Sci Data. 2018;5:180214.

69. Zarrouk A, Romdhane MS, Espinosa F. Reintroduction of the highly endangered mollusk Patella ferruginea Gmelin, 1791 in an MPA: a novel approach to achieve high survival rates. Estuar Coast Shelf Sci. 2018;202:259-69.

70. Germano J, Bishop P. Suitability of amphibians and reptiles for translocation. Conserv Biol. 2009;23:7-15.

71. Tosi G, Chirichella R, Zibordi F, Mustoni A, Giovannini R, Groff C, et al. Brown bear reintroduction in the Southern Alps: to what extent are expectations being met? J Nat Conserv. 2015;26:9-19.

72. Bennett VA, Doerr VAJ, Doerr ED, Manning AD, Lindenmayer DB, Yoon H-J. Habitat selection and post-release movement of reintroduced brown treecreeper individuals in restored temperate woodland. PLOS ONE. 2012;7:e50612. 
73. Muller LI, Murrow JL, Lupardus JL, Clark JD, Yarkovich JG, Stiver WH, et al. Genetic structure in Elk persists after translocation. J Wildl Manag. 2018;82:1124-34

74. Watts $C$, Thornburrow D. Where have all the weta gone? Results after two decades of transferring a threatened New Zealand giant weta, Deinacrida mahoenui. J Insect Conserv. 2008;13:287-95.

75. Goldenberg SZ, Owen MA, Brown JL, Wittemyer G, Oo ZM, Leimgruber P. Increasing conservation translocation success by building social functionality in released populations. Glob Ecol Conserv. 2019;18:e00604.

76. Tarszisz E, Dickman CR, Munn AJ. Physiology in conservation translocations. Conserv Physiol. 2014;2. https://www.ncbi.nlm.nih.gov/pmc/artic les/PMC4732500/. Accessed 14 June 2021.

77. Kenup CF, Sepulvida R, Kreischer C, Fernandez FAS. Walking on their own legs: unassisted population growth of the agouti Dasyprocta leporina, reintroduced to restore seed dispersal in an Atlantic Forest reserve. Oryx. 2018:52:571-8.
78. Bennett VA, Doerr VAJ, Doerr ED, Manning AD, Lindenmayer DB. The anatomy of a failed reintroduction: a case study with the Brown Treecreeper. Emu Austral Ornithol. 2012;112:298-312.

79. Baker J, Bain D, Clarke J, French K. Translocation of the Eastern Bristlebird 2: applying principles to two case studies. Ecol Manag Restor. 2012. https://doi.org/10.1111/j.1442-8903.2012.00640.x.

80. Muths E, Johnson T, Corn P. Experimental repatriation of boreal toad (Bufo boreas) eggs, metamorphs, and adults in Rocky Mountain National Park. Southwest Nat. 2001;46:106

\section{Publisher's Note}

Springer Nature remains neutral with regard to jurisdictional claims in published maps and institutional affiliations.
Ready to submit your research? Choose BMC and benefit from:

- fast, convenient online submission

- thorough peer review by experienced researchers in your field

- rapid publication on acceptance

- support for research data, including large and complex data types

- gold Open Access which fosters wider collaboration and increased citations

- maximum visibility for your research: over 100M website views per year

At BMC, research is always in progress.

Learn more biomedcentral.com/submissions 